\title{
Updated Calculations for Routine Space-Shielding Radiation Dose Estimates: SHIELDOSE-2
}

Stephen M. Seltzer

U.S. DEPARTMENT OF COMMERCE

Technology Administration

National Institute of Standards and Technology

Gaithersburg, MD 20899

Prepared for:

National Aeronautics and Space Administration

Washington, DC 20024

QC 



\section{Updated Calculations for Routine Space-Shielding Radiation Dose Estimates: SHIELDOSE-2}

\section{Stephen M. Seltzer}

U.S. DEPARTMENT OF COMMERCE Technology Administration National Institute of Standards and Technology

Gaithersburg, MD 20899

Prepared for:

National Aeronautics and Space Administration Washington, DC 20024

December 1994

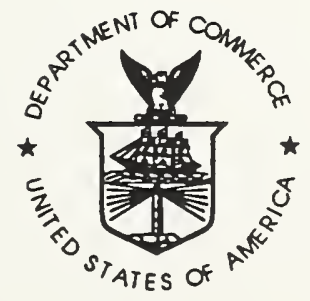

U.S. DEPARTMENT OF COMMERCE Ronald H. Brown, Secretary

TECHNOLOGY ADMINISTRATION Mary L. Good, Under Secretary for Technology

NATIONAL INSTITUTE OF STANDARDS AND TECHNOLOGY

Arati Prabhakar, Director 



\title{
Updated Calculations for
}

\section{Routine Space-Shielding Radiation Dose Estimates ${ }^{1}$ :}

\section{SHIELDOSE-2}

\author{
Stephen M. Seltzer \\ Ionizing Radiation Division \\ National Institute of Standards and Technology \\ Gaithersburg, MD 20899, USA
}

\begin{abstract}
New, more-extensive, depth-dose distributions for electrons, electron-bremsstrahlung, and protons have been calculated, based on improvements in cross-section information since the development of the original SHIELDOSE code. The new database covers incident electron energies from $5 \mathrm{keV}$ to $50 \mathrm{MeV}$, with the bremsstrahlung tail calculated for depths out to $50 \mathrm{~g} / \mathrm{cm}^{2}$, and incident proton energies from $10 \mathrm{keV}$ to $10 \mathrm{GeV}$. Effects of nuclear interactions on proton depth-dose distributions in aluminum shields have been estimated, and options are provided to include these approximations in test calculations. In addition to the absorbed dose in aluminum, the dose in small volumes of graphite, $\mathrm{Si}$, air, bone, $\mathrm{CaF}_{2}, \mathrm{GaAs}, \mathrm{LiF}, \mathrm{SiO}_{2}$, tissue or water can be evaluated. The functionality of new code is much the same as the old code; however, the resultant dose estimates as a function of depth in aluminum spacecraft can be somewhat different. Through the use of a companion code based on approximate transformations, results can be extended beyond the dose as a function of depth in plane slabs and at centers of solid spheres to include the dose at off-center points in a solid sphere and at the inner surface of spherical shells.
\end{abstract}

1 This work was supported by NASA Radiation Health Program, Contract T-9311R. 


\section{Introduction}

Quite sophisticated and accurate computer codes are available to calculate the transport of electrons, the electron-produced bremsstrahlung, and protons through spacecraft material to determine the absorbed dose in a volume of interest. Although such calculations are able to take into account complicated multi-material geometry, they usually require a significant understanding of radiation transport physics in conjunction with knowledge of the often complex geometric details involved, and can involve many hours of computation for each problem. In many situations, it is of value to be able to routinely perform rapid dose estimates based on accurate transport data, even if one is restricted to simple geometries.

The SHIELDOSE code package [1,2] was developed in the late 1970's to provide for such rapid calculations of absorbed dose as a function of depth in the aluminum shielding material of spacecraft, given the electron and proton fluence spectra encountered in orbit. The calculation is based on consideration of a single shielding material (the aluminum that represents the bulk of most spacecraft) and assumes that the fluence of incident radiation is isotropic (at least in the time-averaged sense). Shield geometry is basically limited to simple plane slabs, but - under suitable transformations [3] - the calculated dose distributions can be applied to spherical solids and shells. With these assumptions, the problem was reduced to the development of a basic set of depth-dose distributions in aluminum plane slabs for monoenergetic incident radiation. These could then be used repeatedly to predict the dose for any fluence spectra. Furthermore, with information from the basic calculations on the depth-dependent radiation fluence spectra established in the slab, the dose on small non-perturbing volumes of material other than aluminum can - at least approximately - be estimated. Because the transport of electrons and the associated bremsstrahlung is a complicated process, the basic depth-dose data was developed from detailed Monte Carlo calculations. The proton results were based on calculations in the straight-ahead, continuous-slowing-down approximation.

The SHIELDOSE code has found widespread use for dose estimates by the spaceradiation-effects community. In the nearly 15 years since the original database was developed, much of the underlying transport cross-section information and algorithms have been improved. With NASA support, new basic calculations have been done using current information to update and expand the database, and to improve the software. This report outlines the new work and compares results with those from the original SHIELDOSE.

\section{The Database}

The new database calculations for electrons and bremsstrahlung are based on the up-todate cross-section information and Monte Carlo algorithms described in [4], which also form the basis for the latest version of ITS [5]. The Monte Carlo results, which cover incident electron kinetic energies from $5 \mathrm{keV}$ to $50 \mathrm{MeV}$, are based on much larger numbers of histories than the older calculations, and extend to aluminum depths of $50 \mathrm{~g} / \mathrm{cm}^{2}$. The old database covers electron incident energies from $100 \mathrm{keV}$ to $10 \mathrm{MeV}$ for the direct electron ionization dose and from $20 \mathrm{keV}$ to $20 \mathrm{MeV}$ for the bremsstrahlung dose, extending to aluminum depths of 30 $\mathrm{g} / \mathrm{cm}^{2}$. 
The new proton calculations are based on the use of recent critically-evaluated tables of proton stopping powers and ranges [6], and cover proton energies from $10 \mathrm{keV}$ to $10 \mathrm{GeV}$. The old database covers proton energies from 2 to $5000 \mathrm{MeV}$. The original assumption of straightahead, continuous-slowing-down-approximation (csda) penetration has been maintained, and depth-dose distributions have been prepared both with nuclear interactions taken into account in the aluminum shield, as well with the neglect of nuclear interactions (as done in the old database).

In addition to the absorbed dose in aluminum, the new work includes estimates of the dose in small volumes of graphite, $\mathrm{Si}$, air, bone, $\mathrm{CaF}_{2}, \mathrm{GaAs}, \mathrm{LiF}, \mathrm{SiO}_{2}$, tissue and water. The old SHIELDOSE includes only $\mathrm{Al}, \mathrm{Si}, \mathrm{SiO}_{2}$, and water.

\section{Electron Component}

Monte Carlo calculations for the electron component were carried out using an updated version of the ETRAN code [4], taking into account energy-loss straggling, multiple-elasticscattering angular deflections, the production and transport of all generations of knock-on electrons, bremsstrahlung photons, and characteristic $\mathrm{x}$ rays and Auger electrons subsequent to ionization events. Calculations were done for an incident angular distribution that corresponds to an isotropic fluence of electrons incident on a semi-infinite plane slab aluminum target, with monoenergetic initial kinetic energies of $0.005,0.01,0.02,0.05,0.1,0.2,0.5,1.0,2.0,5.0$, $10.0,20.0$, and 50.0 MeV. Each run was based on the analysis of $100 \mathrm{k}$ incident electron histories, with all radiations followed until either they escaped the target or their energy fell below $1 \mathrm{keV}$. Scores, as a function of depth out to 1.25 times the mean electron range, were kept of the absorbed dose and of the forward-directed and backward-directed fluence spectra of electrons. As the bremsstrahlung component was developed separately to be added to the electron component, secondary electrons from bremsstrahlung photons were not included in these scores.

The absorbed-dose distributions in the semi-infinite aluminum plane slab targets, $D_{\infty}^{\mathrm{Al}}\left(z, T_{\mathrm{o}}\right)$, were scaled and smoothed as functions of both depth $z$ and incident energy $T_{\mathrm{o}}$ using least-square cubic splines [7]. This was done to facilitate the interpolation done over incident spectra in the SHIELDOSE code. To convert these depth-dose distributions to those for detector volumes other than aluminum and for finite-thickness aluminum slabs, the cavity theory of Spencer and Attix [8] was used. Here the cavity is assumed to be of small size so as not to perturb the electron fluence, and we further assume that the electron fluence at the transmission face of a finite-thickness plane slab is closely approximated by the forward-directed electron fluence at the corresponding depth in a slab of much greater thickness. 
Then for semi-infinite slabs,

$$
\frac{D_{\infty}^{\text {det }}\left(z, T_{\mathrm{o}}\right)}{D_{\infty}^{\mathrm{Al}}\left(z, T_{\mathrm{o}}\right)}=\frac{\int_{\Delta}^{T_{\mathrm{o}}} F_{\mathrm{e}}^{\mathrm{tot}}\left(T, z, T_{\mathrm{o}}\right)\left[\frac{L(T, \Delta)}{\rho}\right]^{\mathrm{det}} \mathrm{d} T+F_{\mathrm{e}}^{\mathrm{tot}}\left(\Delta, z, T_{\mathrm{o}}\right)\left[\frac{S(\Delta)}{\rho}\right]^{\mathrm{det}} \Delta}{\int_{\Delta}^{T_{\mathrm{o}}} F_{\mathrm{e}}^{\mathrm{tot}}\left(T, z, T_{\mathrm{o}}\right)\left[\frac{L(T, \Delta)}{\rho}\right]^{\mathrm{Al}} \mathrm{d} T+F_{\mathrm{e}}^{\text {tot }}\left(\Delta, z, T_{\mathrm{o}}\right)\left[\frac{S(\Delta)}{\rho}\right]^{\mathrm{Al}} \Delta},
$$

and for finite-thickness slabs,

$$
\frac{D_{-}^{\mathrm{det}}\left(z, T_{\mathrm{o}}\right)}{D_{\infty}^{\mathrm{Al}}\left(z, T_{\mathrm{o}}\right)}=\frac{\int_{\Delta_{\mathrm{e}}}^{T_{\mathrm{o}}} F_{\mathrm{e}}^{\mathrm{for}}\left(T, z, T_{\mathrm{o}}\right)\left[\frac{L(T, \Delta)}{\rho}\right]^{\mathrm{det}} \mathrm{d} T+F_{\mathrm{e}}^{\mathrm{for}}\left(\Delta, z, T_{\mathrm{o}}\right)\left[\frac{S(\Delta)}{\rho}\right]^{\operatorname{det}} \Delta}{\int_{\mathrm{o}}^{T_{\mathrm{o}}} F_{\mathrm{et}}^{\mathrm{tot}}\left(T, z, T_{\mathrm{o}}\right)\left[\frac{L(T, \Delta)}{\rho}\right]^{\mathrm{Al}} \mathrm{d} T+F_{\mathrm{e}}^{\mathrm{tot}}\left(\Delta, z, T_{\mathrm{o}}\right)\left[\frac{S(\Delta)}{\rho}\right]^{\mathrm{Al}} \Delta},
$$

where $F_{\mathrm{e}}\left(T, z, T_{\mathrm{o}}\right)$ is the electron fluence spectrum (forward and total, as indicated) as a function of spectral energy $T$ and depth $z, L(T, \Delta) / \rho$ is the electron restricted mass collision stopping power, restricted to energy losses less than $\Delta, S(T) / \rho$ is the unrestricted mass collision stopping power, and $\Delta$ is a cut-off energy generally associated with the size of the cavity. The values of $\Delta$ were chosen as $\max \left(T_{\mathrm{o}} / 5000,1 \mathrm{keV}\right)$, which places them between 10 and $1 \mathrm{keV}$; the calculated dose ratios should be rather insensitive to these choices.

Electron stopping powers were calculated according to the methods given in ICRU Report 37 [9]; the composition of bone and tissue was assumed that of cortical bone and of soft tissue given in ICRU Report 44 [10]. Note that the assumptions of our calculations lead to results that pertain only to suitably small volumes of detector material in the aluminum absorber. For example, the results might apply to a bone- or tissue-equivalent detector rather than to an extended biological target. Some scaling and smoothing of the stopping-power ratios were done to facilitate interpolation.

\section{Bremsstrahlung Component}

The ETRAN Monte Carlo calculations were carried out in a fashion similar to that for the electron component, treating the same set of monoenergetic incident electron kinetic energies. In these cases, however, each calculation was based on $100 \mathrm{k}$ incident electrons and a sample of $10 \mathrm{M}$ emitted bremsstrahlung photons, followed down to an energy of $1 \mathrm{keV}$. The calculation treats the usual photon interactions: pair and triplet production, incoherent (Compton) scattering, coherent scattering, and photoelectric absorption. These Monte Carlo simulations improve on our older calculations in that updated cross-section information is used and coherent scattering and binding corrections in incoherent scattering are included. Secondary charged particles were followed to include their contribution to bremsstrahlung production. The photon fluence spectra were scored out to depths of $50 \mathrm{~g} / \mathrm{cm}^{2}$ of aluminum. 
With the assumption of charged-particle equilibrium, the absorbed dose from bremsstrahlung photons in the aluminum absorber was calculated according to

$$
D_{\infty}^{\mathrm{Al}}\left(z, T_{\mathrm{o}}\right)=\int_{\mathrm{o}}^{T_{\mathrm{o}}} F_{\gamma}^{\mathrm{tot}}\left(k, z, T_{\mathrm{o}}\right) k\left(\frac{\mu_{\mathrm{en}}(k)}{\rho}\right)^{\mathrm{Al}} \mathrm{d} k,
$$

where $F_{\gamma}\left(k, z, T_{\mathrm{o}}\right)$ is the photon fluence spectrum as a function of spectral energy $k$ and depth $z$, and $\mu_{\mathrm{en}}(k) / \rho$ is the photon mass energy-absorption coefficient. Dose ratios were obtained for semi-infinite slabs from,

$$
\frac{D_{\infty}^{\text {det }}\left(z, T_{0}\right)}{D_{\infty}^{\mathrm{Al}}\left(z, T_{\mathrm{o}}\right)}=\frac{\int_{0}^{T_{0}} F_{\gamma}^{\mathrm{tot}}\left(k, z, T_{0}\right)\left[\frac{\mu_{\mathrm{en}}(k)}{\rho}\right]^{\mathrm{det}} \mathrm{d} k}{\int_{0}^{T_{0}} F_{\gamma}^{\mathrm{tot}}\left(k, z, T_{\mathrm{o}}\right)\left(\frac{\mu_{\mathrm{en}}(k)}{\rho}\right)^{\mathrm{Al}} \mathrm{d} k},
$$

and for finite-thickness slabs from,

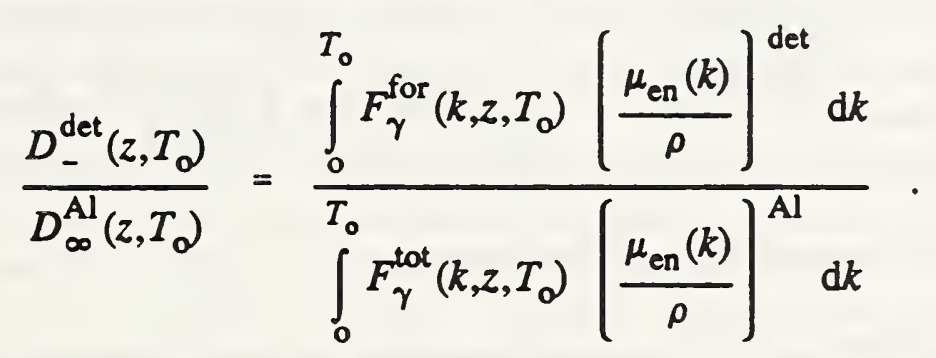

Values for $\mu_{e n}(k) / \rho$ were obtained from calculations recently outlined by Seltzer [11]. Some scaling and smoothing of the $\mu_{\text {en }}$ ratios were done to facilitate interpolation.

For detector materials other than aluminum, the use of dose ratios defined in terms of the photon mass energy-absorption coefficient raises an issue of potential importance. The assumption here is that the detector size is small enough that it does not significantly perturb the photon fluence, but large enough that the energy absorbed in the detector is predominantly from secondary electrons produced by the photons in the detector material and not from those produced in the aluminum absorber or wall material. As an example, for a small graphite-wall air ionization chamber it seems more correct to consider the detector to be the graphite wall, as the ionization in the air is predominantly from the electrons produced in the graphite build-up material. Other situations can be more complicated and may not be adequately treated in our approximation. 


\section{Proton Component}

Depth-dose distributions were calculated for an isotropic fluence of protons incident on a semi-infinite plane slab aluminum targets, with monoenergetic initial kinetic energies of 0.01 , $0.015,0.02,0.03,0.04,0.05,0.06,0.08,0.1, \ldots ., 1000,1500,2000,3000,4000,5000$, 6000,8000 , and $10000 \mathrm{MeV}$. Current information on proton stopping powers and ranges in the materials of interest has been taken from the recent ICRU Report [6]. A special set of calculations was needed for GaAs which was not included in the work of the ICRU Report Committee. The compositions for tissue and bone were those for ICRU striated muscle and for ICRP cortical bone, both given in reference [9]. In the straight-ahead (neglect of elastic scattering angular deflections) and continuous-slowing-down (neglect of energy-loss straggling) approximations, the depth dose can be calculated from a relatively simple numerical evaluation. A comparison of these results with those from a full Monte Carlo calculation confirm the overall adequacy of using these approximations for such calculations, particularly for isotropic fluences. In the straight-ahead approximation (and very nearly in the actual case), there is no distinction between forward-directed and total fluence. The dose in the various detector materials has been obtained from the integral of the product of the fluence spectrum and the stopping power:

$$
\frac{D_{\infty}^{\text {det }}\left(z, T_{\mathrm{o}}\right)}{D_{\infty}^{\mathrm{Al}}\left(z, T_{\mathrm{o}}\right)}=\frac{\int_{0}^{T_{0}} F_{\mathrm{p}}^{\mathrm{tot}}\left(T, z, T_{\mathrm{o}}\right)\left[\frac{S(T)}{\rho}\right]^{\mathrm{det}} \mathrm{d} T}{\int_{0}^{T_{\mathrm{o}}} F_{\mathrm{p}}^{\mathrm{tot}}\left(T, z, T_{\mathrm{o}}\right)\left[\frac{S(T)}{\rho}\right]^{\mathrm{Al}} \mathrm{d} T},
$$

where here $S(T) / \rho$ is the proton mass stopping power.

The original SHIELDOSE calculations ignored effects of nuclear interactions, i.e., the attenuation of the primary proton beam and the production and transport of nuclear-reaction products. Earlier work by Santoro et al. [12] indicated that the neglect of such effects tended to give conservative (somewhat higher) dose estimates, and that the differences can be significant, perhaps as large as $30-40 \%$ for hard proton spectra and shield thicknesses of $50 \mathrm{~g} / \mathrm{cm}^{2}$. It is difficult to develop guidelines based on such essentially anecdotal findings, so it was considered worthwhile to incorporate in the new code an approximate model of nuclear interactions to provide at least a crude estimate of the effects.

The attenuation of the primary proton beam due to nonelastic nuclear interactions requires knowledge of the total nonelastic-nuclear-interaction cross section. The cross-section data for aluminum shown in Fig. 1 include measured values compiled by Bauhoff [13], the fitted results of intranuclear-cascade calculations [14], the results adopted by Janni [15], the values calculated by Townsend and Wilson [16], and the curve adopted here. Our solid curve has been drawn mainly as a fit to the experimental data, constrained by the high-energy asymptotic value of approximately $456 \mathrm{mb}[17]$ and by a threshold implied by the first excited state in nuclear level 
diagrams ${ }^{2}$. From the adopted total cross sections, one can calculate the attenuation of primary protons along the direction of travel, as shown in Fig. 2. Integrating over the proton slowing down, the fraction of the number and of the energy of primary protons lost in nuclear interactions can be obtained and is shown in Fig. 3 .

The fate of the energy lost in nuclear interactions is, however, a more complicated problem. Results from reference [14] indicate that the relative abundance of nuclear-reaction products in aluminum should be approximately the same as that for oxygen, allowing the use of data recently developed for protons in water [18]. Assuming that the charged-particle nuclear secondaries are short-ranged, their energy can be assumed to be absorbed at the point of production $^{3}$. Figure 4 gives the fraction of primary energy converted to charged-particle secondaries and assumed to be locally absorbed, as obtained from reference [18] and assigned here to proton collisions in aluminum. Then, taking into account attenuation and the local deposition of charged-particle secondaries, an absorbed dose can be calculated as a function of distance along the direction of travel. Such depth-dose curves, with and without nuclear interactions, are shown in Fig. 5, and indicate rather small effects for protons with energies up to a few hundred $\mathrm{MeV}$, but rather significant effects at the higher energies. That proton spectra for typical applications fall off rapidly at such high energies would seem to mitigate the effect of our approximations.

The energy converted to secondary neutron energy (and de-excitation gamma-ray energy) cannot be assumed locally at orbed. The amount of energy involved is shown in Fig. 6 from integrations over the proton slowing down, assuming the partition of primary energy to nuciearreaction products from reference [18]. These results indicate only a relatively small fraction of primary energy is converted to secondary neutrons for protons up to about one hundred $\mathrm{MeV}$, somewhat larger for the less-abundant high-energy proton. One option is to assume that such energy completely escapes the region of interest. Another option that has been considered is to assume - rather crudely - that the total neutron energy produced by the incident proton is exponentially distributed (from the entrance surface) with a attenuation coefficient of $0.03 \mathrm{~cm}^{2} / \mathrm{g}$ in alumirum. This numerical value was taken from tables of the "removal" cross section for fast neutrons in aluminum in references [19-21], and is roughly consistent with the "relaxation" length reported for fast neutrons in aluminum [22].

Figure 7 shows proton absorbed-dose distributions in aluminum from calculations (a) neglecting nuclear interactions, (b) including nuclear attenuation and only our assumption of the local absorption of secondary charged-particle energy, and (c) as in (b) plus adding our approximate distribution of deposited neutron energy. The calculations pertain to protons with simple exponential spectra, extending from $1 \mathrm{MeV}$ to $10 \mathrm{GeV}$, characterized by e-folding energies $\alpha$ from 10 to $200 \mathrm{MeV}$. Our estimates of the fraction of the beam energy converted to neutron energy are $0.000033,0.00061,0.0090,0.033$, and 0.084 , for $\alpha$-values of $10,20,50$,

2 Values of the cross section at low energies are rather unimportant in the present application because the effects are small and tend to occur toward the end of the proton range, involving little energy.

3 Secondary proton spectra have tails extending to energies close to the primary energy, for which our negligible-range approximation is no longer justified. Unfortunately, for high incident primary proton energies, secondary protons dominate the distribution of nuclear-reaction products. 
100 , and $200 \mathrm{MeV}$, respectively. The differences are informative, but our approximations cannot be considered particularly reliable. For soft spectra, the small amount of neutron energy distributed exponentially becomes prominent at large depths, but at a level many orders of magnitude lower in dose. For hard spectra, the doses calculated with our approximations for nuclear-interaction effects cam become larger than those without, which does not conform with the results in reference [12] and implies a failure of our simple approximations (see footnote 3 and Fig. 5).

Because of the uncertainties associated with the treatment of nuclear-interaction effects, and because the dose ratios used to convert to dose in detector materials other than aluminum apply strictly only to the primary beam without nuclear attenuation, it is recommended that reliance not be placed on the use of these approximations, but used perhaps to gauge possible effects that might require more accurate follow-up. It should also be kept in mind that only the physical absorbed dose has been addressed here; high-LET effects associated with the heavier secondaries are beyond the scope of this work.

\section{Comparisons of Results}

It is useful to compare results from the old and new SHIELDOSE codes. Because the volume of monoenergetic data is so large, it is difficult to completely describe the differences between the new and old work. As expected for the direct electron ionization and for the proton depth-dose distributions, the differences are not large (less than a few to perhaps as much 10 percent) for the same incident energy. Differences in the bremsstrahlung depth-dose distributions can be larger, depending on incident energy and depth, due mainly to the use of new bremsstrahlung production spectra.

To facilitate some comparisons, test calculations have been done for simple exponential spectra of electrons and protons incident on semi-infinite aluminum slabs, assuming the detector material to also be Al. Differences between results from SHIELDOSE and from SHIELDOSE-2 are due not only to differences in the basic monoenergetic data but also due to differences in the coverage of the databases and the numerical techniques used in the interpolation and integration over input spectra. To establish some comparability, spectra were integrated from $1 \mathrm{MeV}$ up to $10 \mathrm{GeV}$ for protons and from $10 \mathrm{keV}$ up to $20 \mathrm{MeV}$ for electrons and bremsstrahlung, relying on the automatic (but not reliable) scaling of depth-dose distributions outside the covered energy ranges of the old SHIELDOSE database.

For incident proton spectra with e-folding energies from 5 to $200 \mathrm{MeV}$, and considering only cases without nuclear attenuation, small differences (less than $3 \%$ ) are found in the dose at depths less than about $1 \mathrm{~g} / \mathrm{cm}^{2}$, as shown in Fig. 8. At larger depths, the new doses are larger by from $3 \%$ for the harder spectra to as much as $10-20 \%$ for the soft spectra. For incident electron spectra with e-folding energies from 0.1 to $5 \mathrm{MeV}$, Fig. 9 indicates that the differences are less than about $5 \%$ for depths out to $1-3 \mathrm{~g} / \mathrm{cm}^{2}$. At larger depths out to $30 \mathrm{~g} / \mathrm{cm}^{2}$, the differences in the bremsstrahlung tail of the dose distribution becomes evident, with the new results smaller by from $0-10 \%$ for the hardest spectrum to about $40-60 \%$ for the softest spectrum. 
Some comparisons among SHIELDOSE-2 results highlight the larger list of detector materials included. Figure 10 shows ratios of proton doses for one detector to those for another, for exponential spectra incident on aluminum slabs: Fig. 10a for Si/LiF; 10b for GaAs/Al; 10c for $\mathrm{GaAs} / \mathrm{Si}$; $10 \mathrm{~d}$ for $\mathrm{GaAs} / \mathrm{CaF}_{2}$. Similar results, but for the electron and bremsstrahlung dose, are given in Fig. 11: Fig. 11a for $\mathrm{Si} / \mathrm{CaF}_{2}$; $11 \mathrm{~b}$ for $\mathrm{GaAs} / \mathrm{Al}$; 11c for $\mathrm{GaAs} / \mathrm{Si}$; 11d for $\mathrm{GaAs} / \mathrm{CaF}_{2}$. The rather large dose ratios that can be predicted in the bremsstrahlung tail, particularly for detector materials of largely differing effective atomic number, should serve as a reminder about the interpretation of detector size and configuration, as mentioned earlier.

\section{Concisions}

Improvements in cross-section information and numerical methods have been incorporated into the SHIELDOSE database, and the coverage has been extended. Differences in the resultant dose estimates have been explored, but the significance of possible changes has to be determined for the depths and spectra pertinent to a particular problem.

Information on running the new SHIELDOSE-2 code can be found in Appendix A. Also included is a companion code DOSCON which can be used to approximately convert the output of SHIELDOSE-2 to obtain the dose for additional geometries: at off-center points in a solid sphere or at the inner surface of spherical shells. Appendix B contains a FORTRAN listing of SHIELDOSE-2, version 2.10, and Appendix C gives the present version of DOSCON. The software for SHIELDOSE-2 should be considered as open, and suggestions are solicited for further development toward enhanced functionality and better flexibility, portability, and ease of use. 


\section{References}

[1] S.M. Seltzer, "Electron, Electron-Bremsstrahlung and Proton Depth-Dose Data for SpaceShielding Applications," IEEE Trans. Nucl. Sci. NS-26, 4896 (1979).

[2] S.M. Seltzer, "SHIELDOSE: A Computer Code for Space-Shielding Radiation Dose Calculations," National Bureau of Standards Technical Note 1116 (1980).

[3] S.M. Seltzer, "Conversion of Depth-Dose Distributions from Slab to Spherical Geometries for Space-Shielding Applications," IEEE Trans. Nucl. Sci. NS-33, 1292 (1986).

[4] S.M. Seltzer, "Electron-Photon Monte Carlo Calculations: The ETRAN Code," Appl. Radiat. Isot. 42, 917 (1991).

[5] J.A. Halbleib, R.P. Kensek, T.A. Mehlhorn, G.D. Valdez, S.M. Seltzer and M.J. Berger, "ITS Version 3.0: The Integrated TIGER Series of Coupled Electron/Photon Monte Carlo Transport Codes," Sandia National Laboratories Report SAND91-1634 (1992).

[6] M.J. Berger, M. Inokuti, H.H. Andersen, H.Bichsel, D. Powers, S.M. Seltzer, D. Thwaites, and D.E. Watt, "Stopping Powers for Protons and Alpha Particles," Report 49 of the International Commission on Radiation Units and Measurements (1993).

[7] M.J.D. Powell, "Curve Fitting by Cubic Splines," Atomic Energy Research Establishment (Harwell) Report TP 307 (1967).

[8] L.V. Spencer and F.H. Attix, "A Theory of Cavity Ionization," Radiat. Res. 3, 239 (1955).

[9] M.J. Berger, M. Inokuti, H.H. Andersen, H.Bichsel, J.A. Dennis, D. Powers, S.M. Seltzer, and J.E. Turner, "Stopping Powers for Electrons and Positrons," Report 37 of the International Commission on Radiation Units and Measurements (1984).

[10] D.R. White, J. Booz, R.V. Griffith, J.J. Spokas, and I.J. Wilson, "Tissue Substitutes in Radiation Dosimetry and Measurement," Report 44 of the International Commission on Radiation Units and Measurements (1989).

[11] S.M. Seltzer, "Calculation of Photon Mass Energy-Transfer and Mass Energy-Absorption Coefficients," Rad. Res. 136, 147 (1993).

[12] R.T. Santoro, R.G. Alsmiller, Jr., and J. Barish, "The Validity of Using Only Primary Protons in Van Allen Belt and Solar-Flare Proton Shielding Studies," Nucl. Sci. and Engr. 49, 395 (1972).

[13] W. Bauhoff, "Tables of Reaction and Total Cross sections for Proton-Nucleus Scattering Below $1 \mathrm{GeV}$," At. Data and Nucl. Data Tables 35, 429 (1986). 
[14] R.G. Alsmiller and J. Barish, "NCDATA - Nuclear Collision Data for Nucleon-Nucleus Collisions in the Energy Range 25 to $400 \mathrm{MeV}$, "Oak Ridge National Laboratory Report ORNL-4220 (1968).

[15] J.F. Janni, "Proton Range-Energy Tables, $1 \mathrm{keV}-10 \mathrm{GeV}$," At. Data and Nucl. Data Tables 27, 147 (1982).

[16] L.W. Townsend and J.W. Wilson, "Tables of Nuclear Cross Sections for Galactic Cosmic Rays," National Aeronautics and Space Administration Reference Publication 1134 (1985).

[17] J.R. Letaw, R. Silberberg, and C.H. Tsao, "Proton-Nucleus Inelastic Cross Sections: An Empirical Formula for E > $10 \mathrm{MeV}$," Astrophys. J. Suppl. Ser. 51, 271 (1983).

[18] S.M. Seltzer, "An Assessment of the Role of Charged Secondaries from Nonelastic Nuclear Interactions by Therapy Proton Beams in Water," National Institute of Standards and Technology Publication NISTIR 5221 (1993).

[19] H.E. Hungerford, "The Nuclear, Physical, and Mechanical Properties of Shielding Materials" in Reactor Handbook, 2nd Edition, Vol. I. Materials (Ed. C.R. Tipton, Jr.), Interscience, NY, p. 1027 (1960).

[20] R. Aronson and C.N. Klahr, "Neutron Attenuation," in Reactor Handbook, 2nd Edition, Vol. III. Materials (Ed. E.P. Blizard, Jr.), Interscience, NY, p. 63 (1962).

[21] P.N. Stevens, D.K. Trubey, C.W. Garrett, and W.E. Selph, "Radiation Transport," in Reactor Shielding for Nuclear Engineers (Ed. N.M. Schaeffer), U.S. Atomic Energy Commission, p. 119 (1973).

[22] D.L. Broder and S.G. Tsypin, "Neutron Attenuation. Attenuation in Non-Hydrogenous Media," in Engineering Compendium on Radiation Shielding, Vol. I. Shielding Fundamentals and Methods (Ed. R.G. Jaeger), Springer-Verlag, NY, p. 322 (1968). 


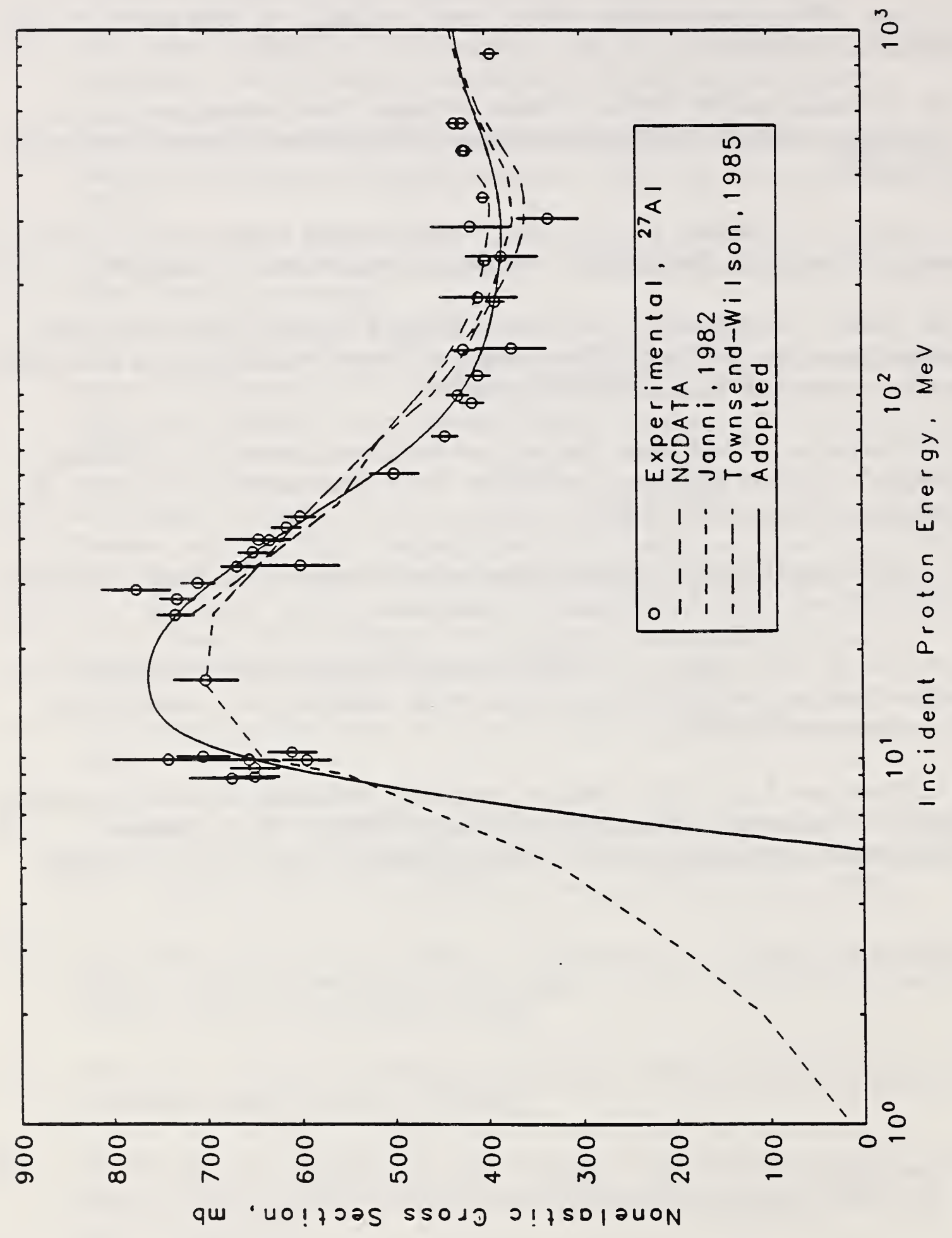

ำ

음

흥

옹

등 믐

过

ฮ

은

인

它

跬

으ํ

ठํํㅇ

흠

है

点

¿

ก

吉

홍

든

훙

$\Phi$

แํㅗㅇ

巳

을

든

吾

告

远

른

는

总 


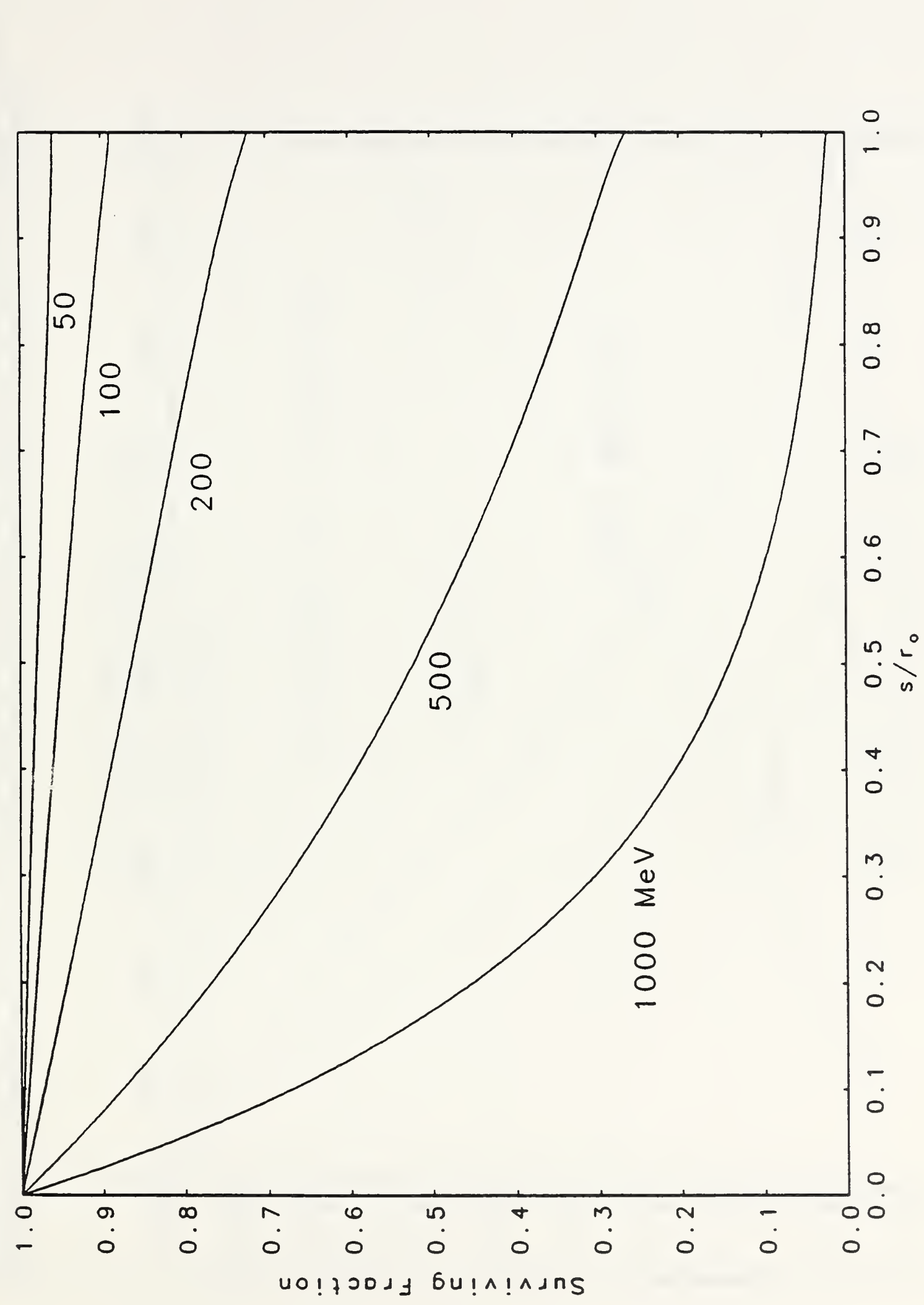

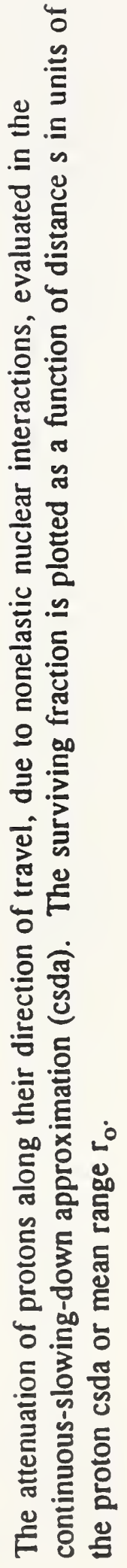




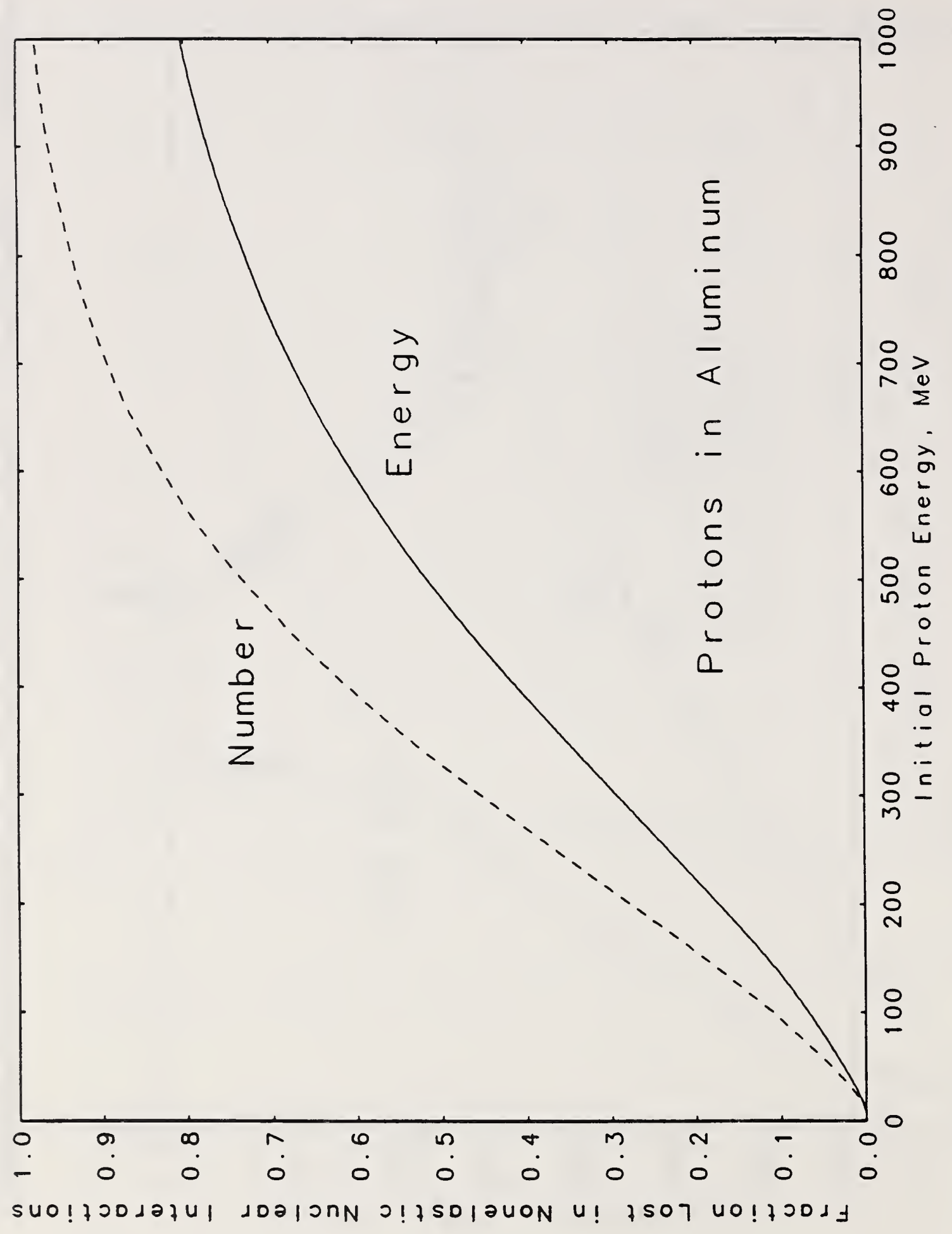

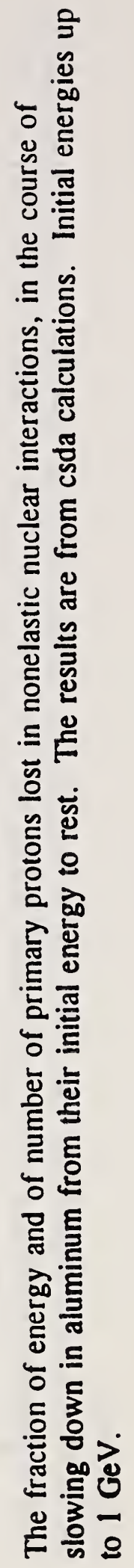




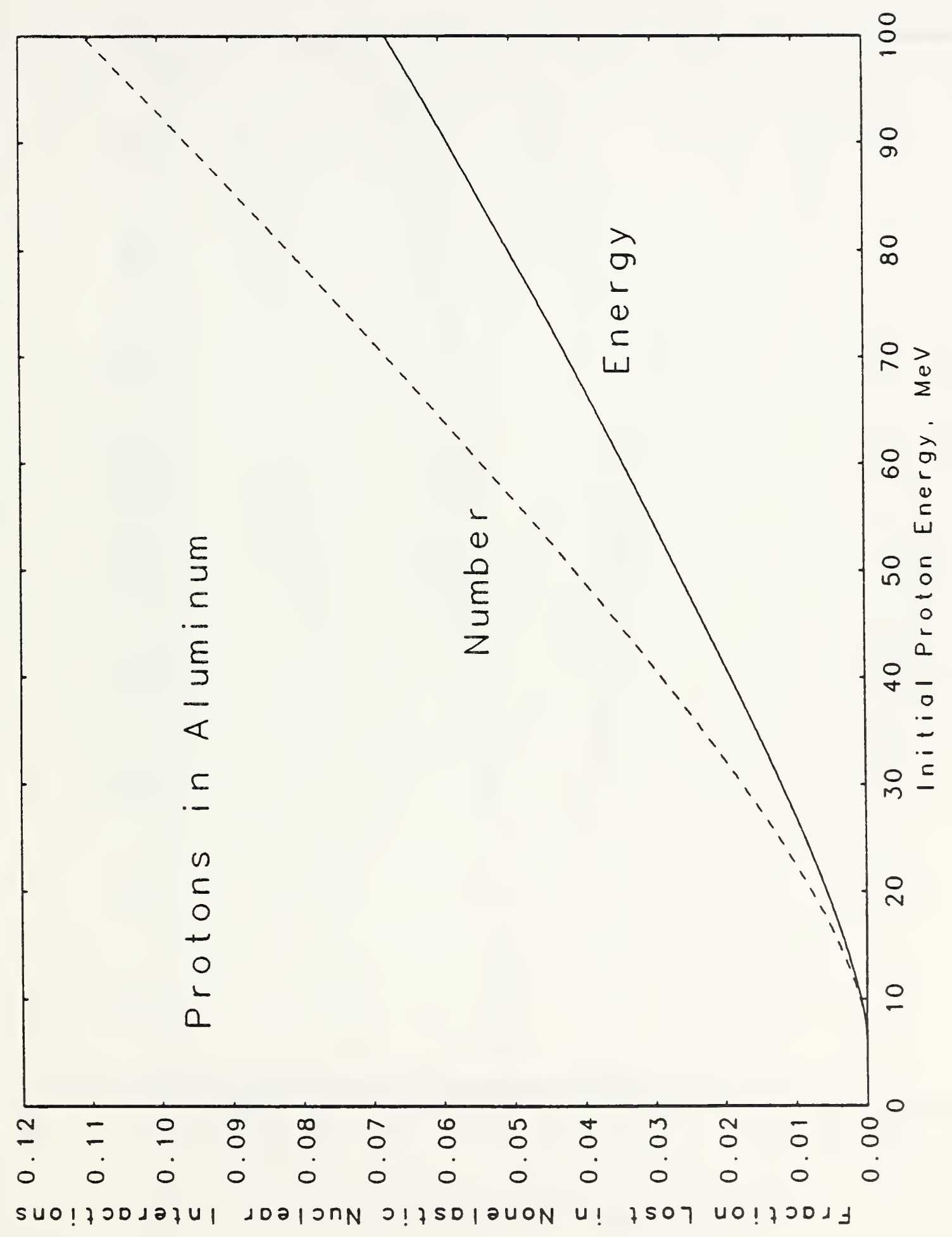

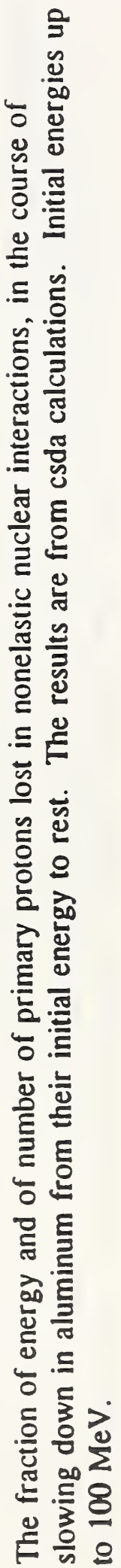




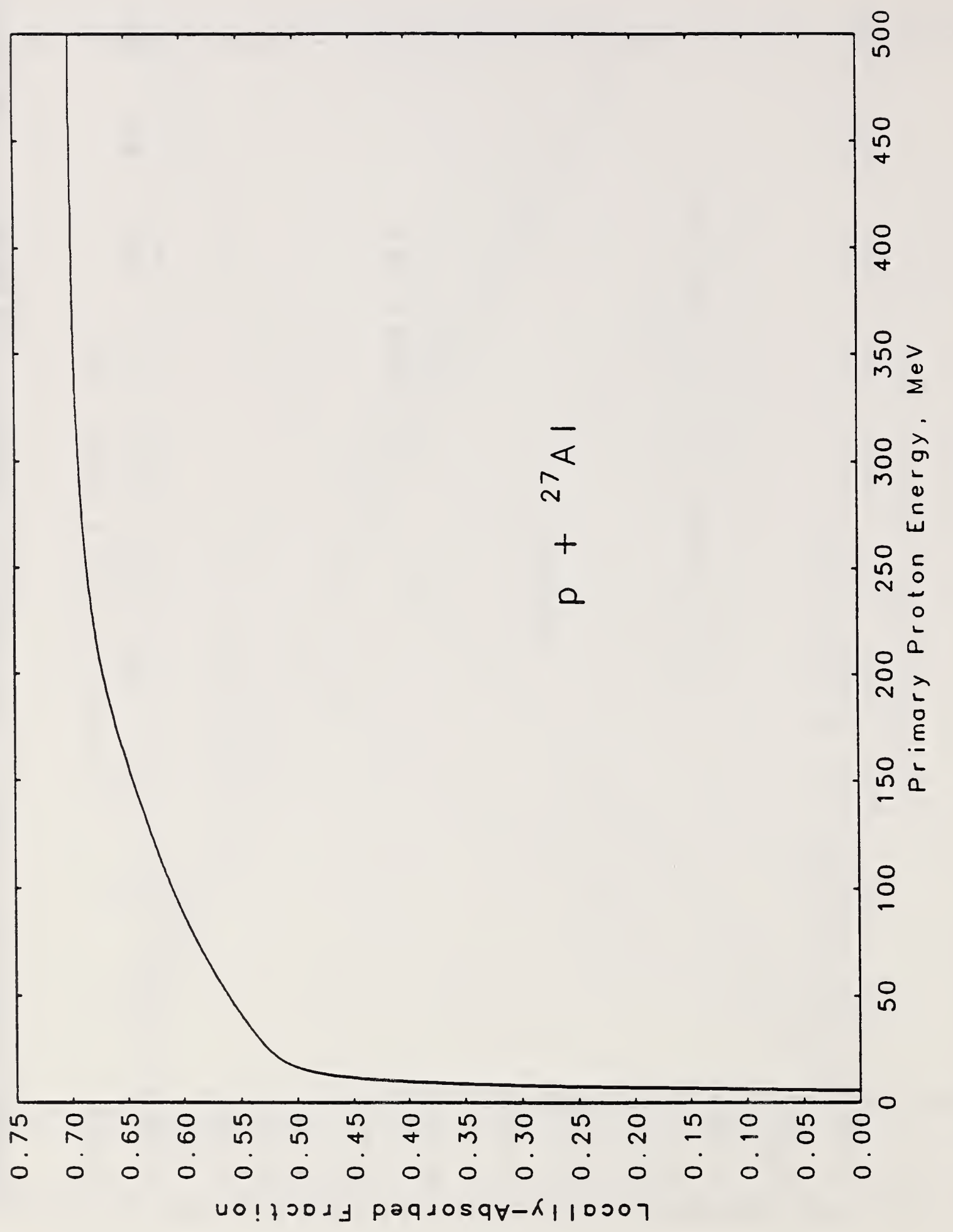

.

글

ํํㅇ

5

ते

능

응

䏠

요

옹

엉 ్ㅗ

त्रे हू

돈

응 을

它.气

है

돈

흐

․ㅡㄴ

등

氖 


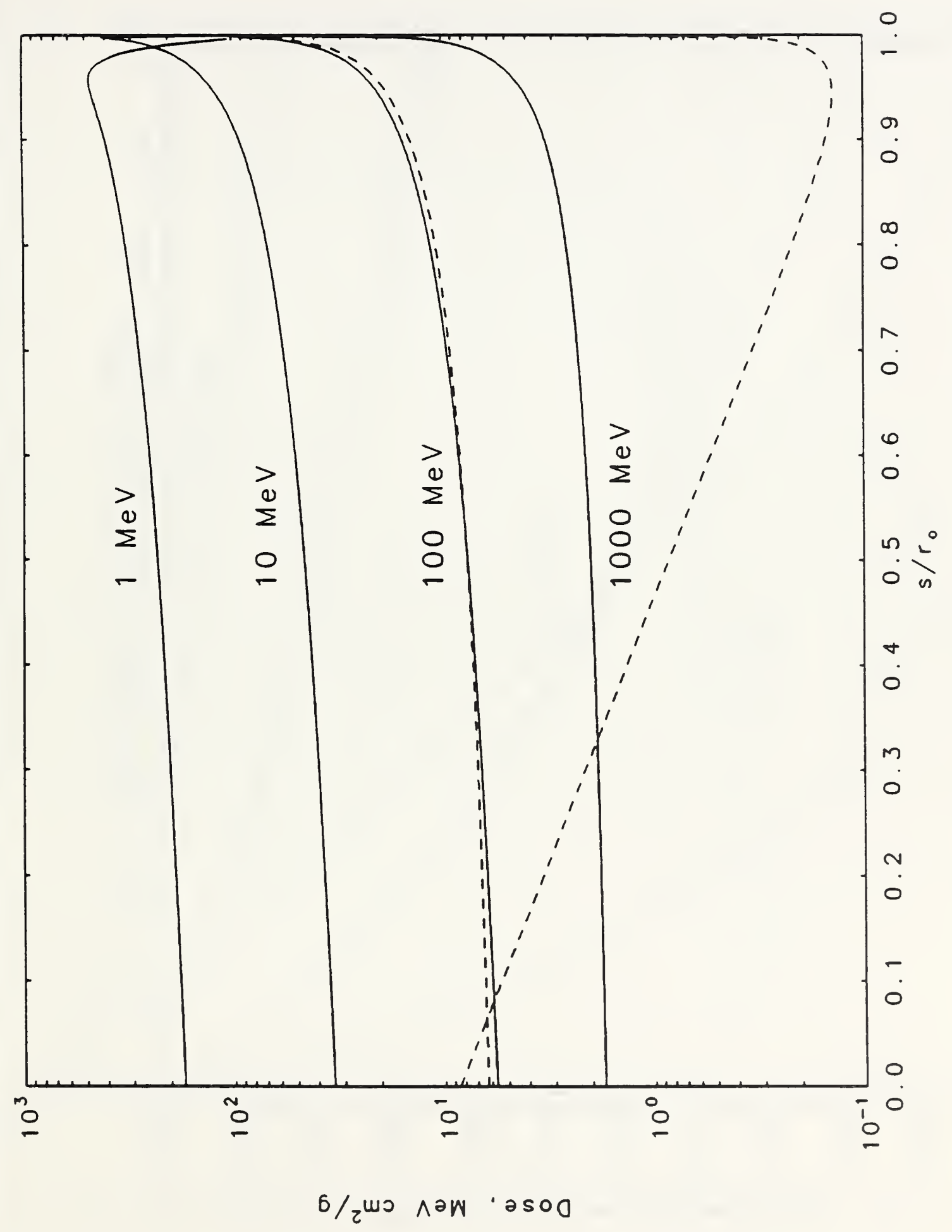

苋

范 흔

क力

ف.

告

읋

ड़

ฮู

훙

흘

원

능

ڤั

路

응ㅎㅇ

웅

苨

ن

过

를

넝 엉

을 응

ङ

든

흐 으

咩

政

y -

造

음 품

일

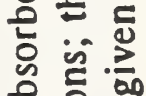

ธิ

응 땡웡

ㄴ.ᅳ

in 


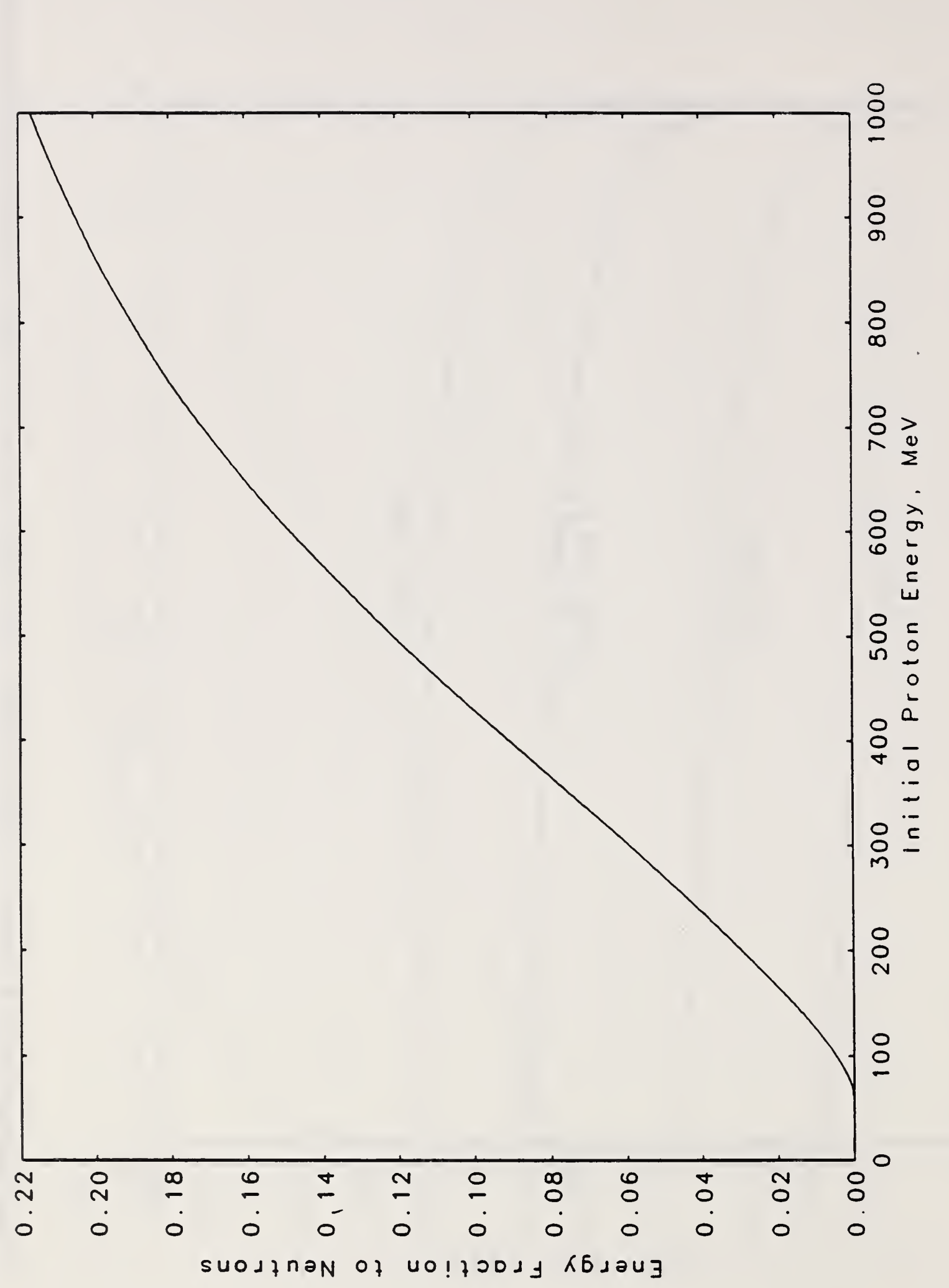

$\stackrel{\mathscr{\Xi}}{\Xi}$

造

离 응

อ 틍

논

ป 닌

을 톨

․

จे

Ð

등 헌

옹 은

ब

응

증

응.

논능

을

을 통

근

ह

흘

ธั के

ํㅗㄴ 


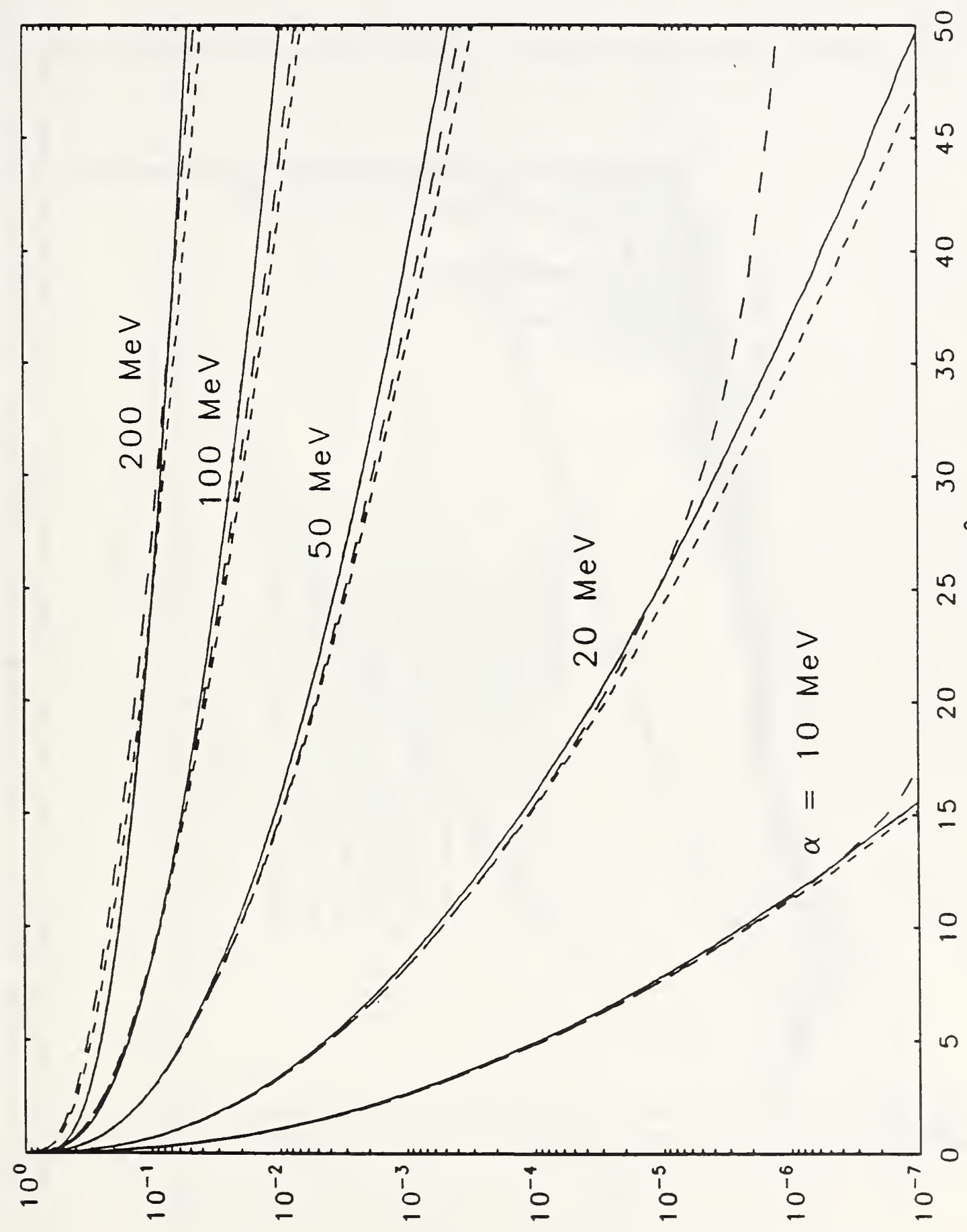

范

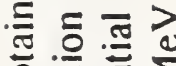

오

늉 ฮ용

行

ฮ ๘

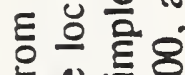

인 壬完

들

仓ั ฮิ

บำำ

믕 츨

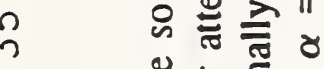

迅产

的部.

究 है है

E

U $\quad \frac{\pi}{2} . \cong$

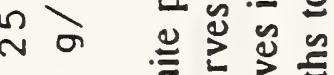

N

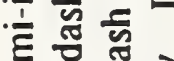

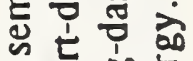

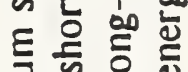

至

药导

สั

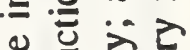

응 훈흥

ㄹ. ฮั อ

흥 느 잉

늘 능. 일

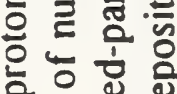

पष

은

خิ

ธิ

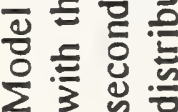

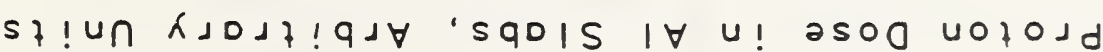

ก் 


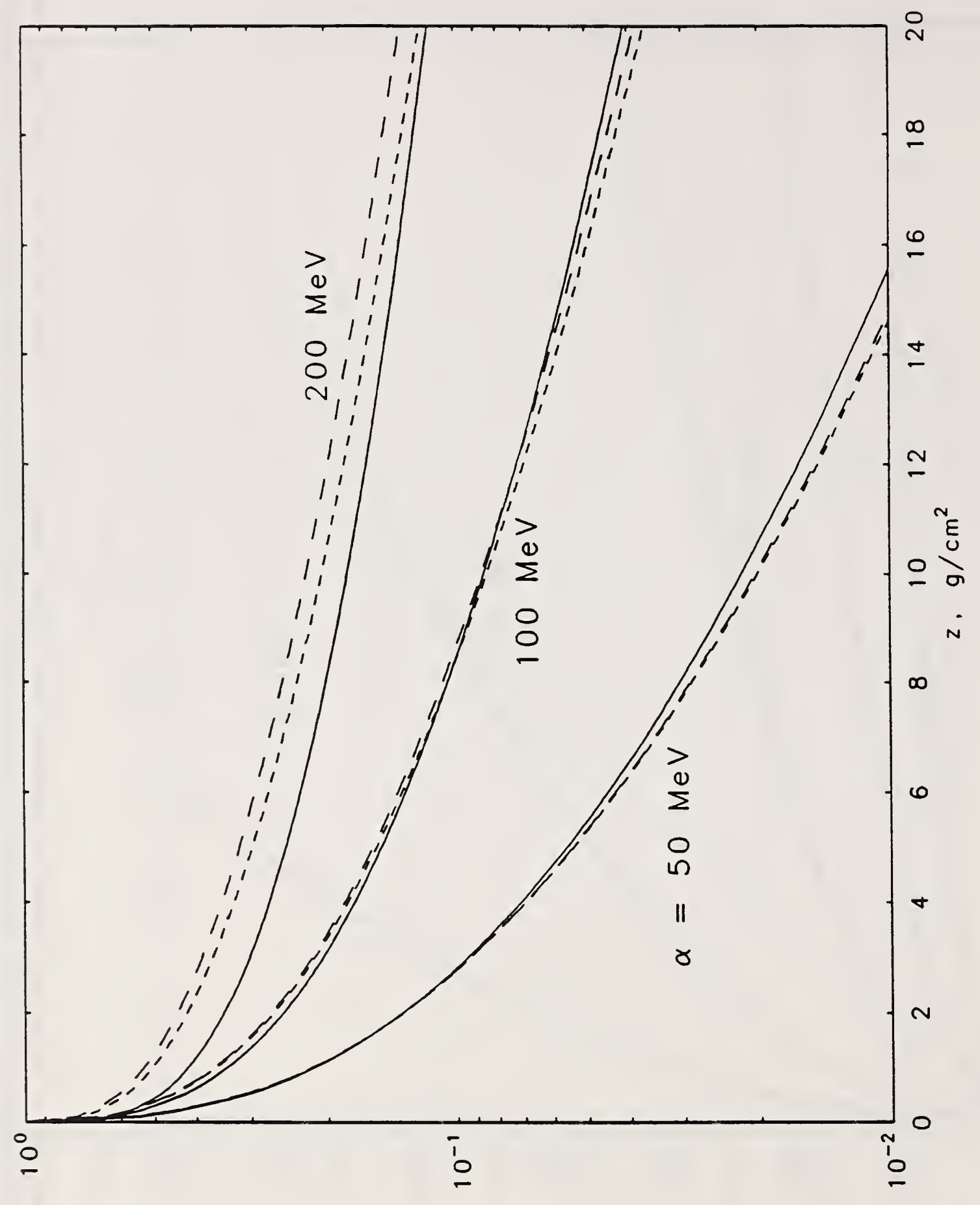

st! un KAost! qA

ఫृ

高

气客

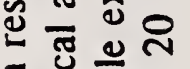

틍으 을 은

次 紊

施

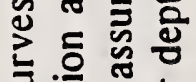

了。

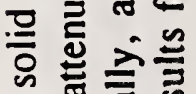

는 온

터을

เ

종 \&

른 을

2..

릴 ญ

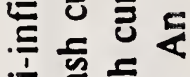

ह तु

论 क्ष

통을 흥

를 을

䒕 论

. 으 흐 ฮ

突

号选卷

… 巳ั

흐웡

음 멍

을 놇

훈 官这

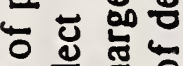

긍

的焉

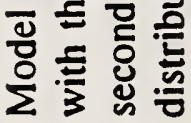

$\stackrel{2}{2}$ 


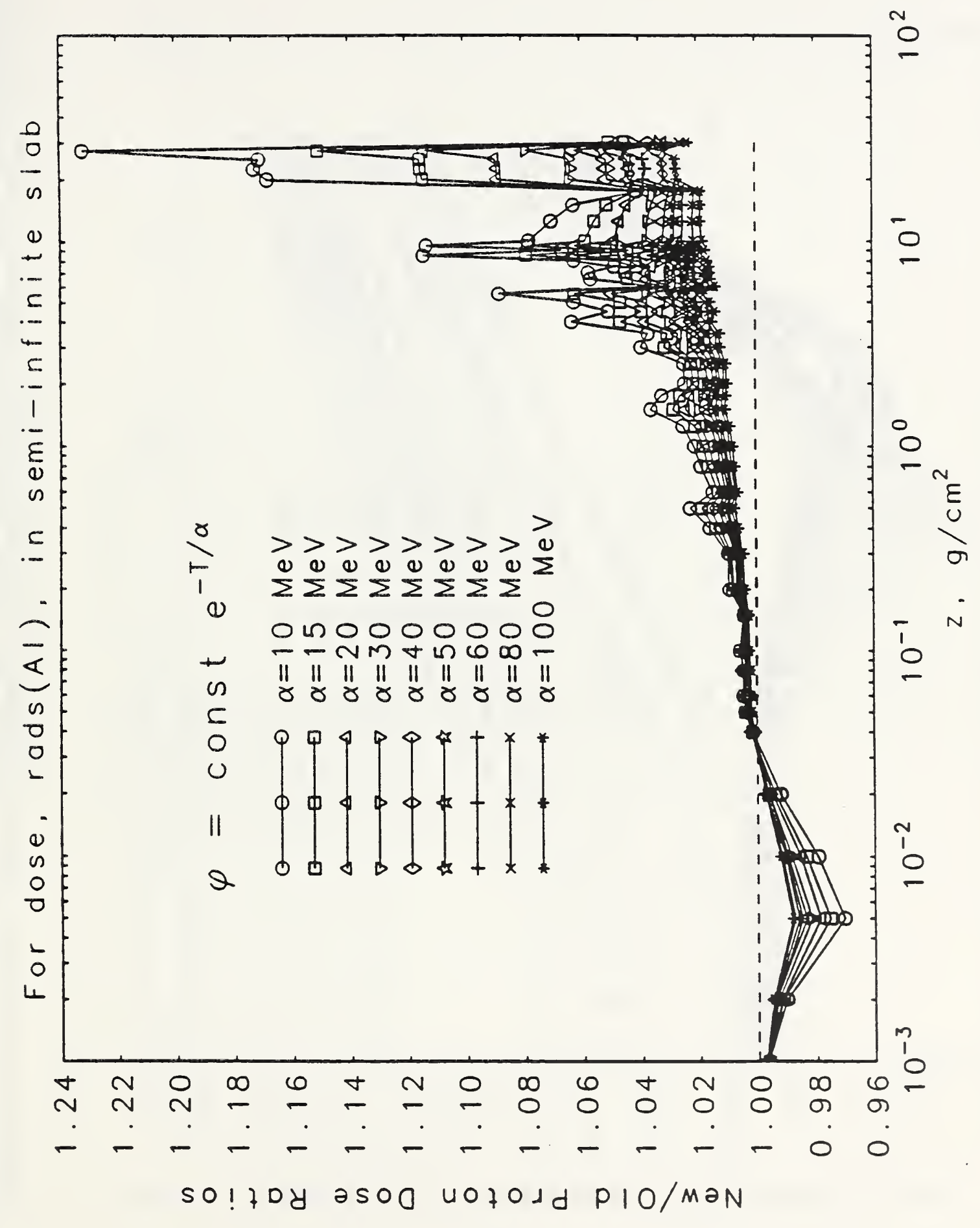

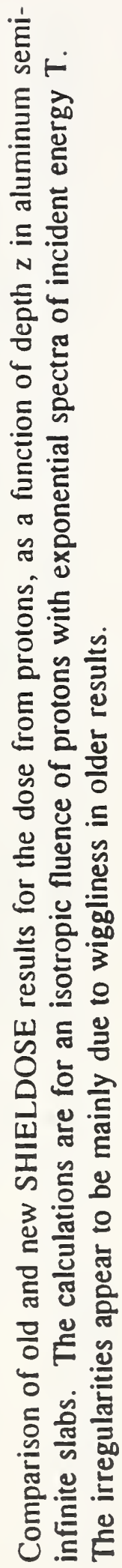

$\infty$ 


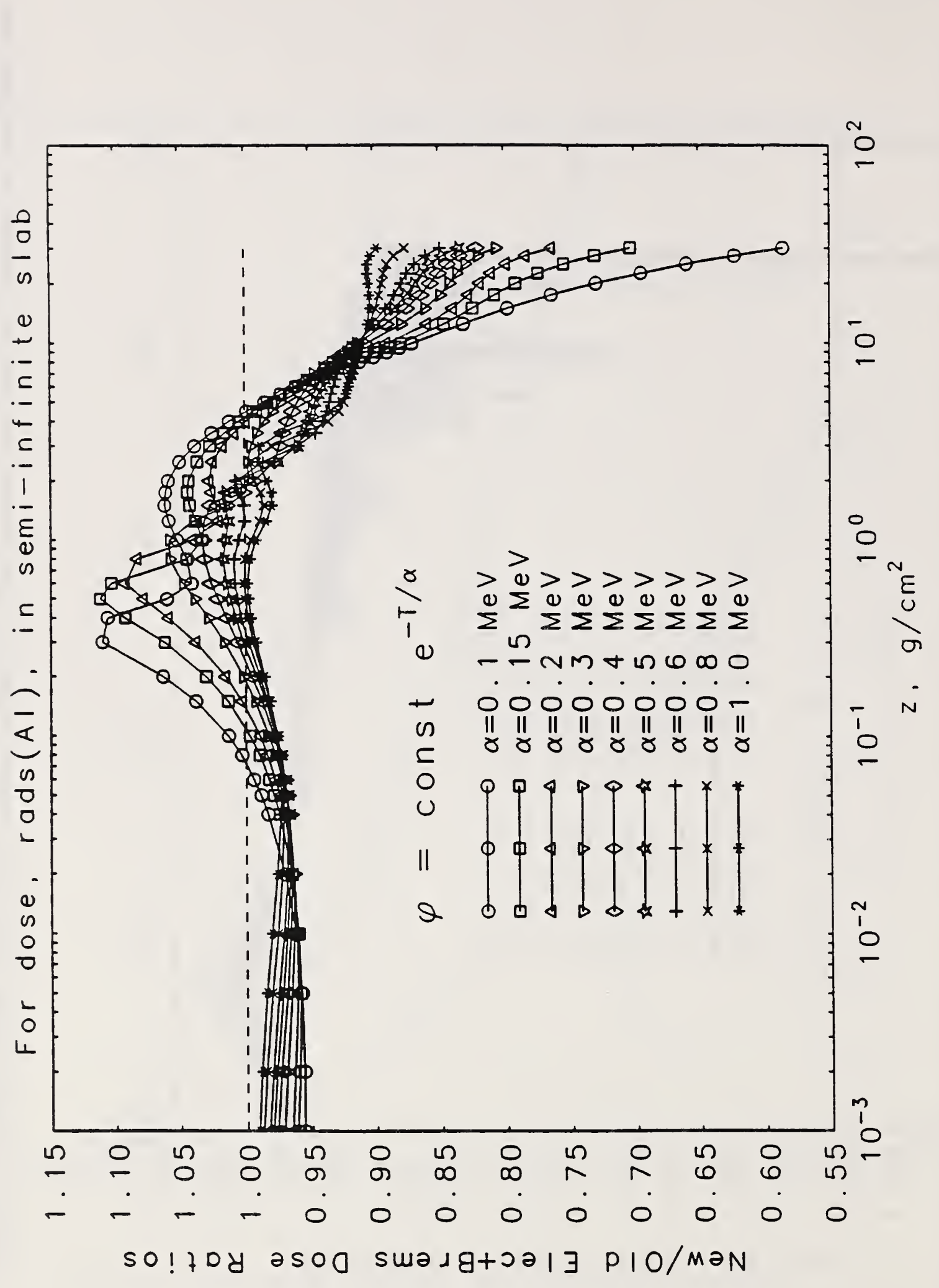

สิ

รั

全

於

ปั้

है

ธัธ

을

는

点 음

్ㅗ ส్

는

บั้ํํ

$\frac{Q}{\omega}$

틍 을

은 죽

ฆิ

음 저

틀

는

产

ญ.

뇐

윽

피 ญू

틀

3 ․ㅡㅇ

톯.음

몽 등

응 손 논

음

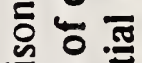

을 응 등

후을

i 


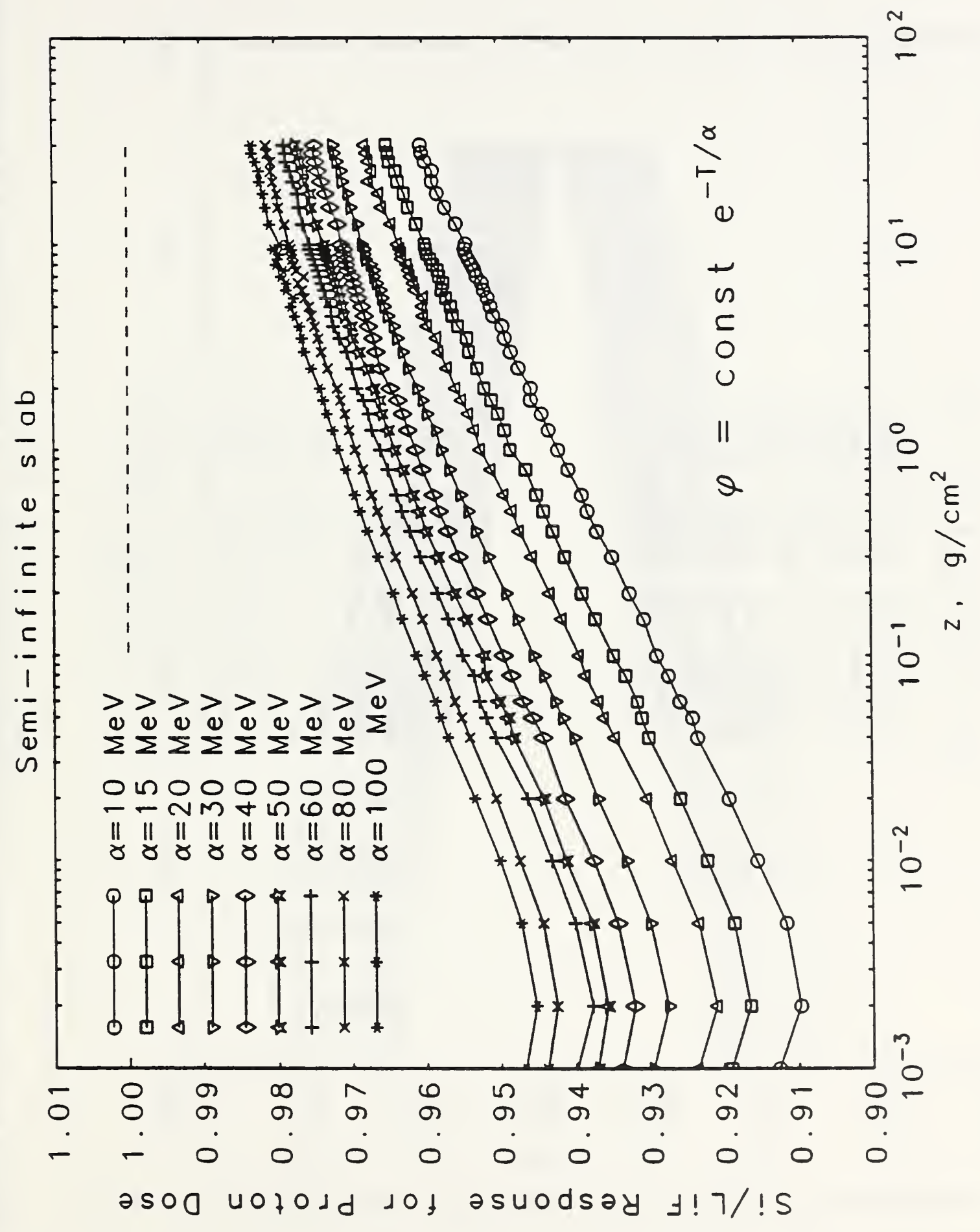

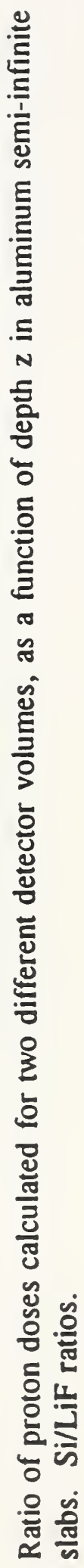

$\stackrel{8}{0}$ 


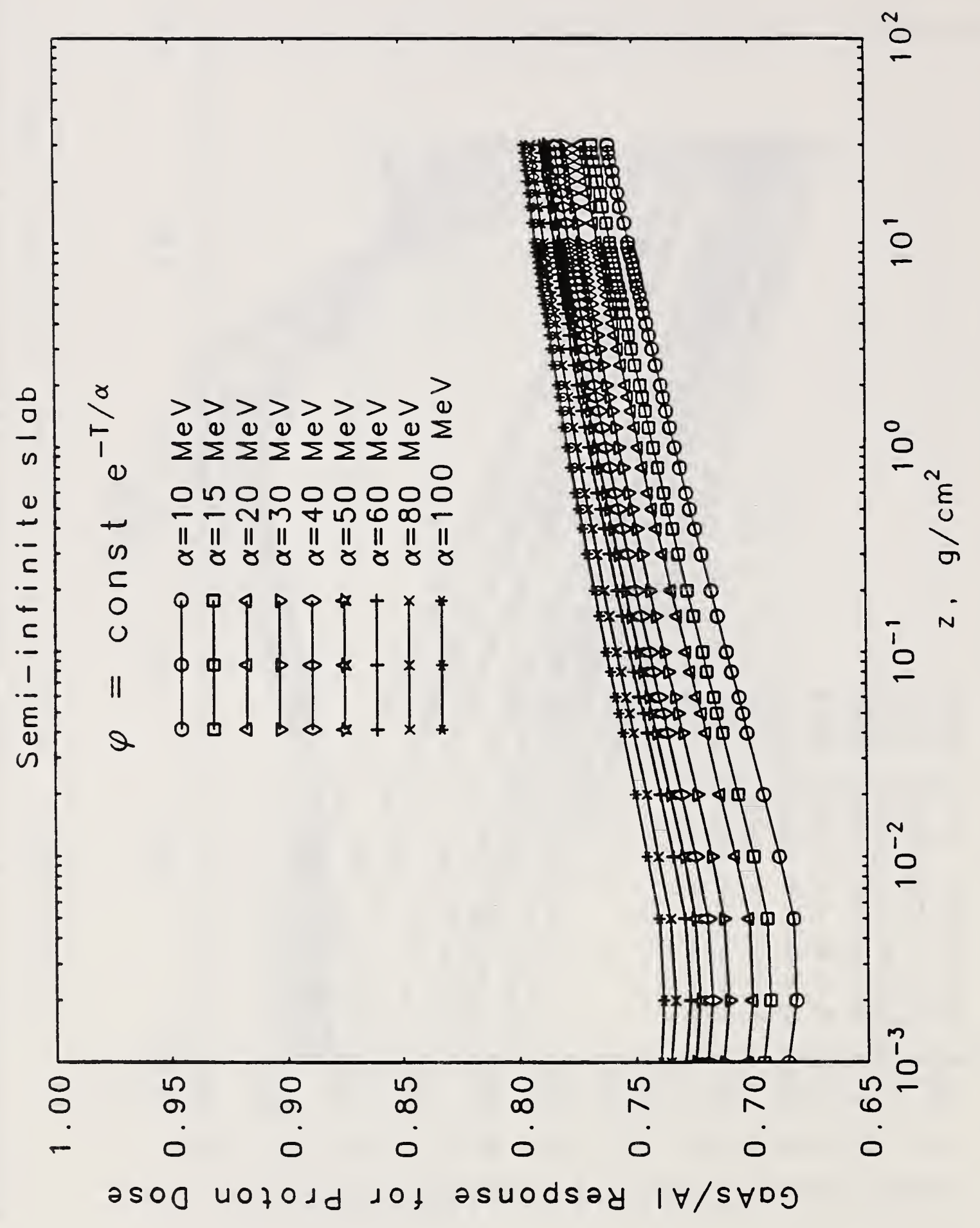

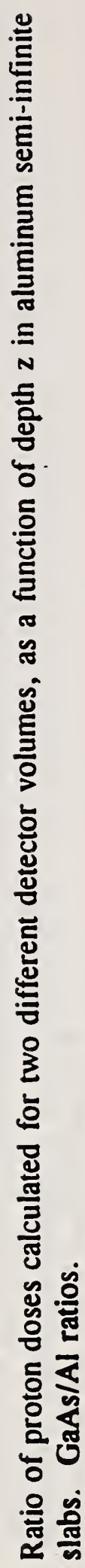

욤 


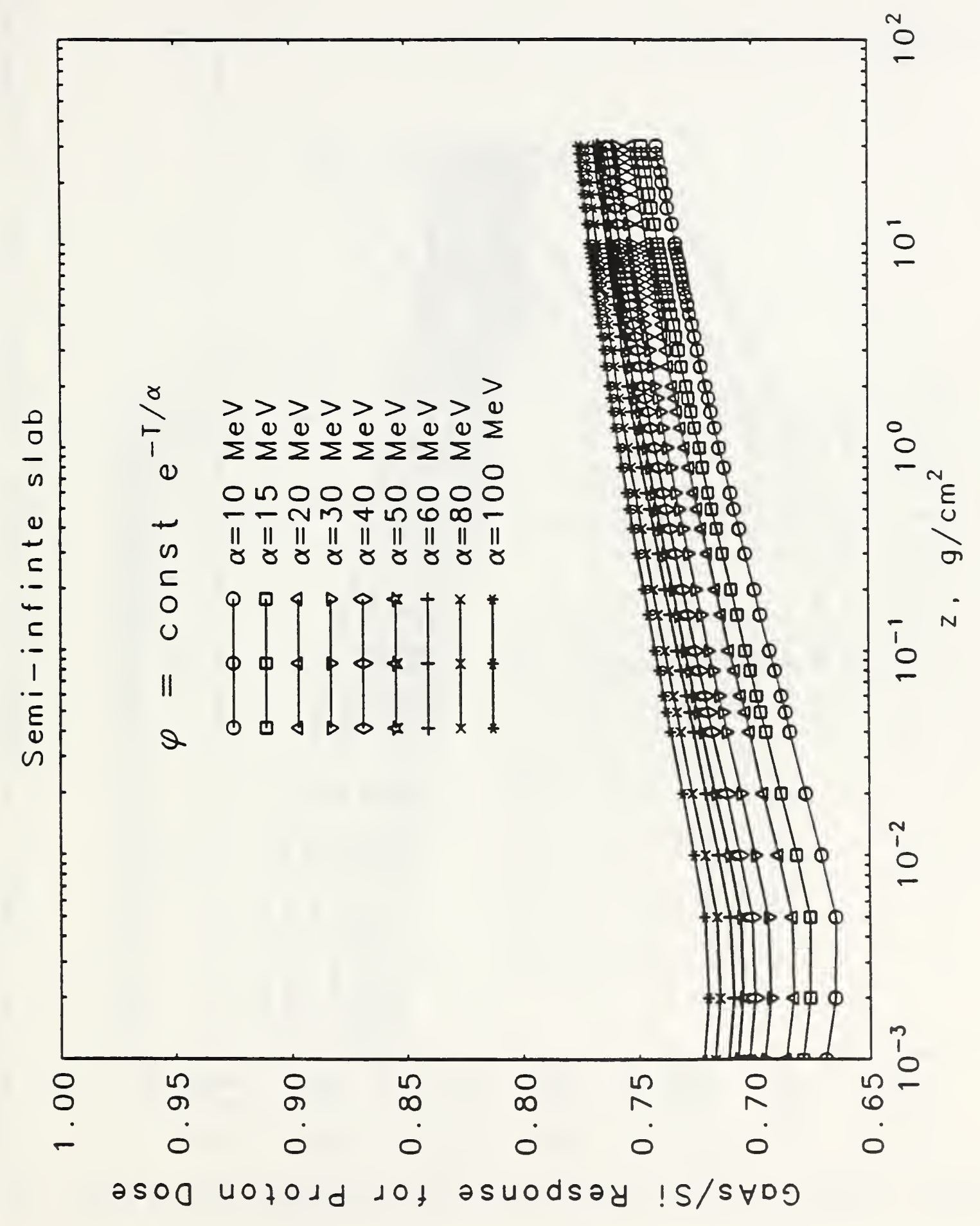

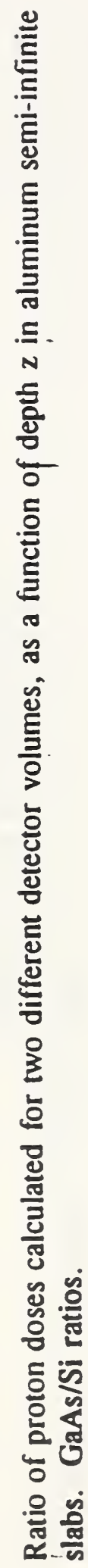

임 


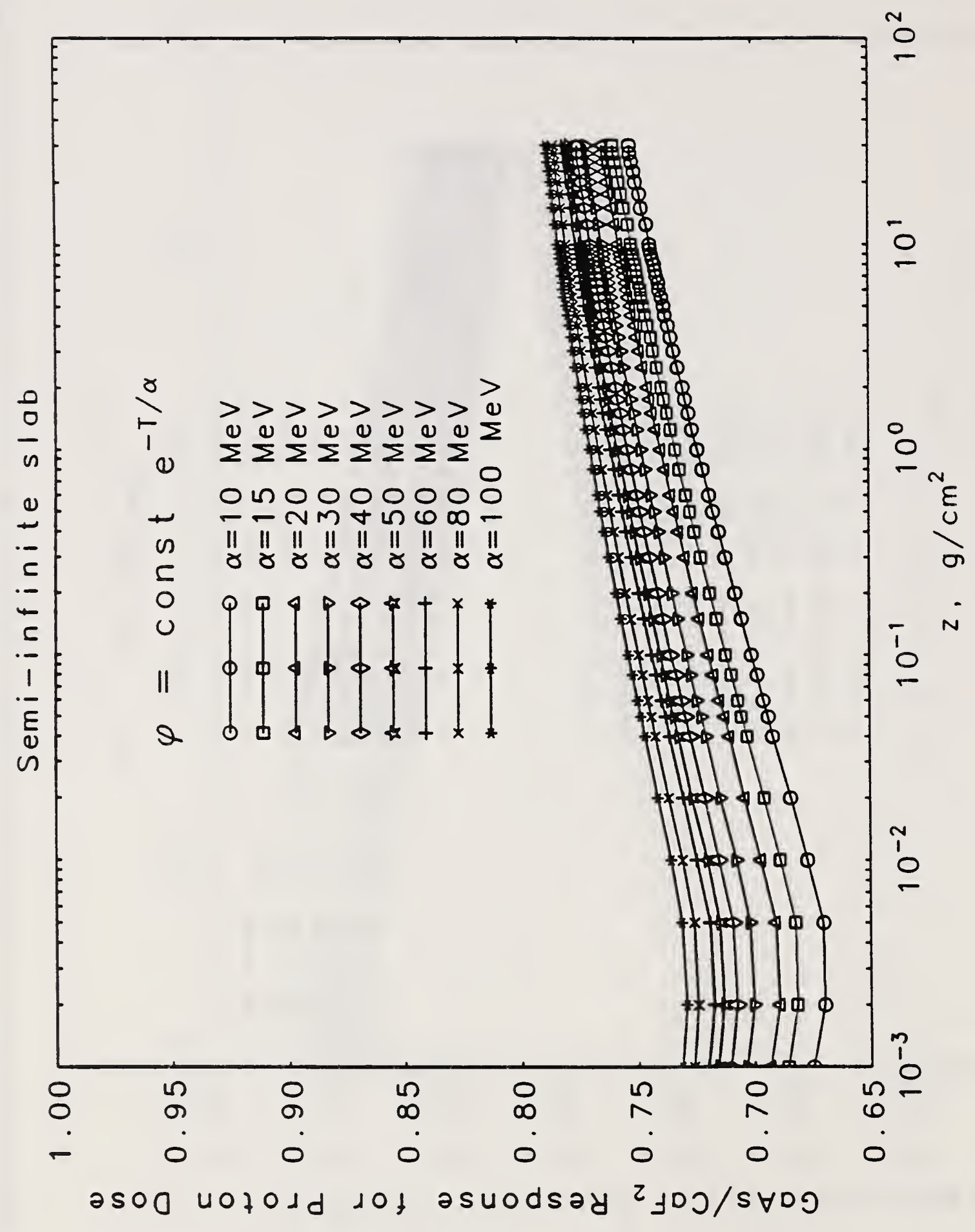

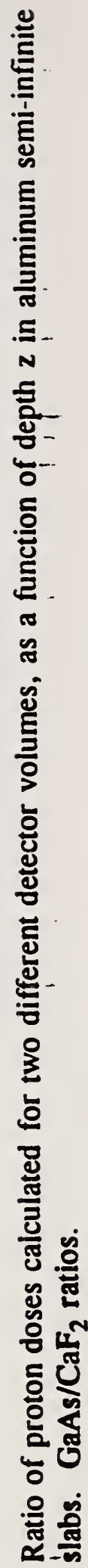

8 


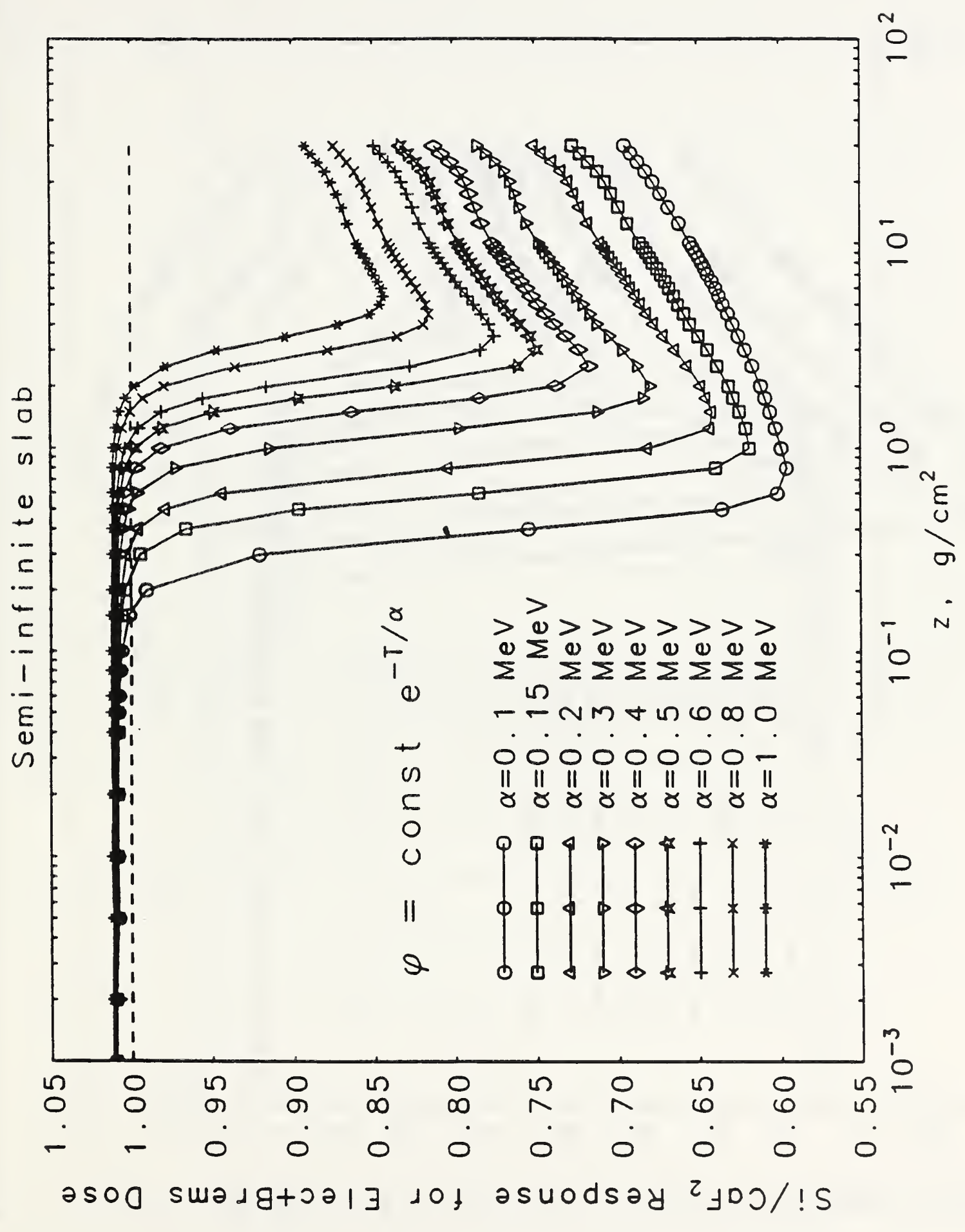

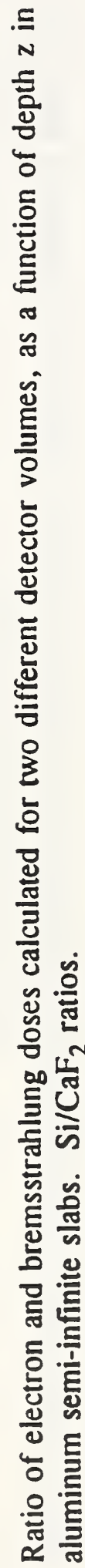

$\stackrel{\text { S }}{=}$ 


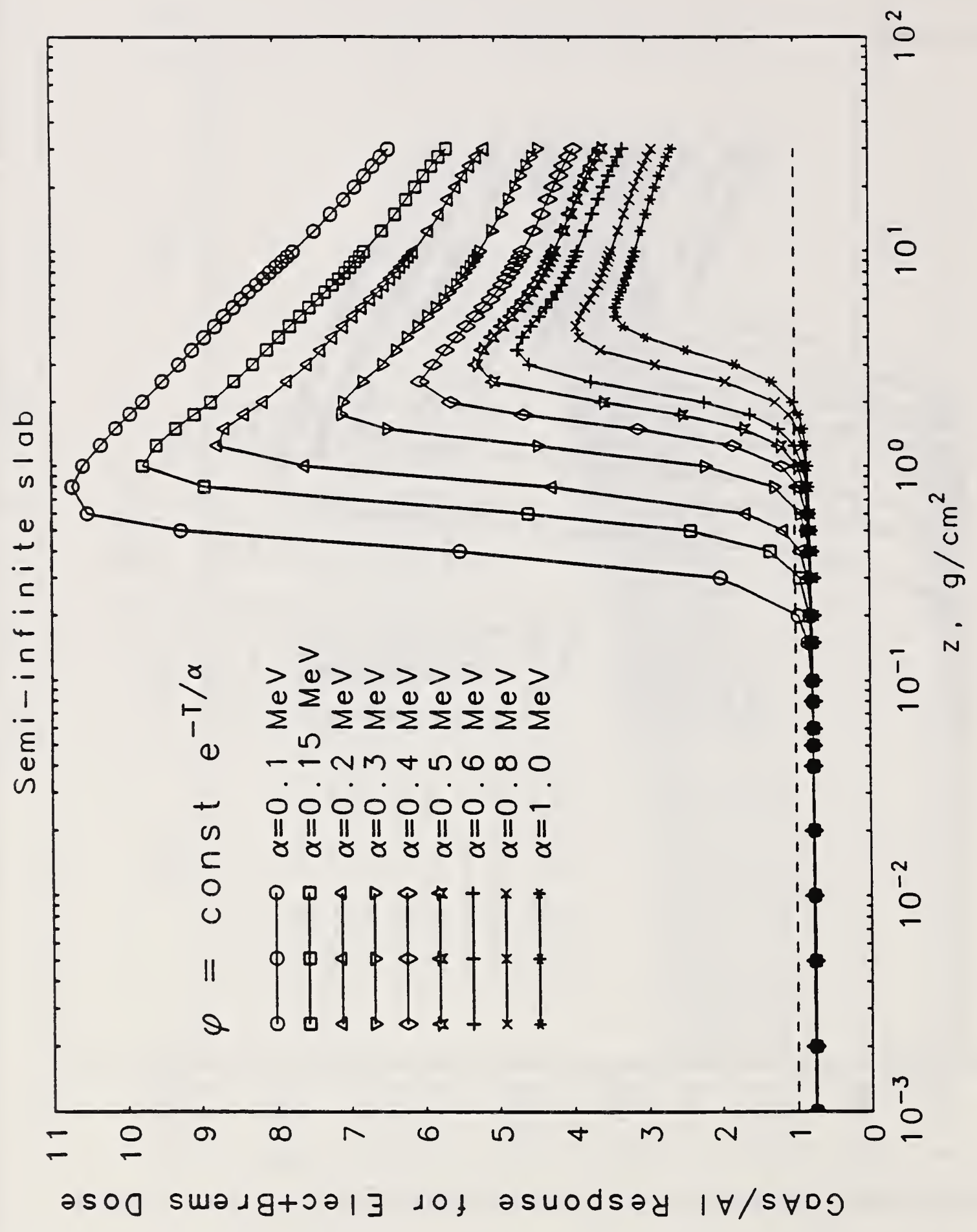

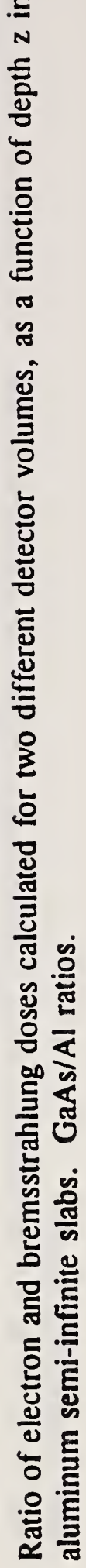




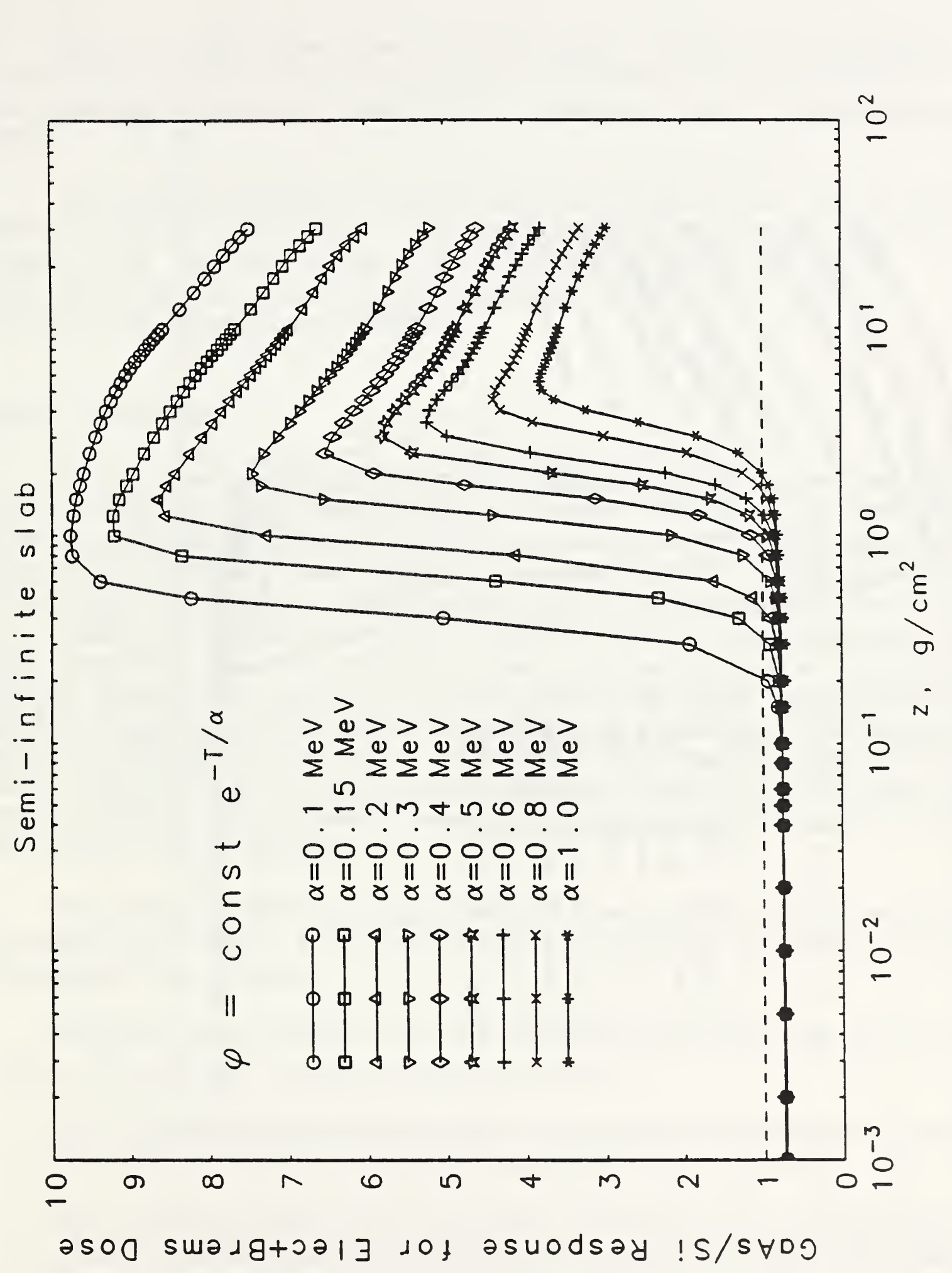

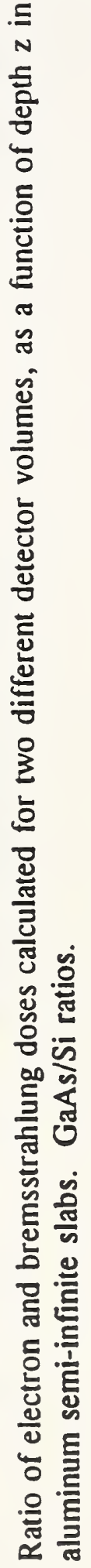

$\underline{2}$ 


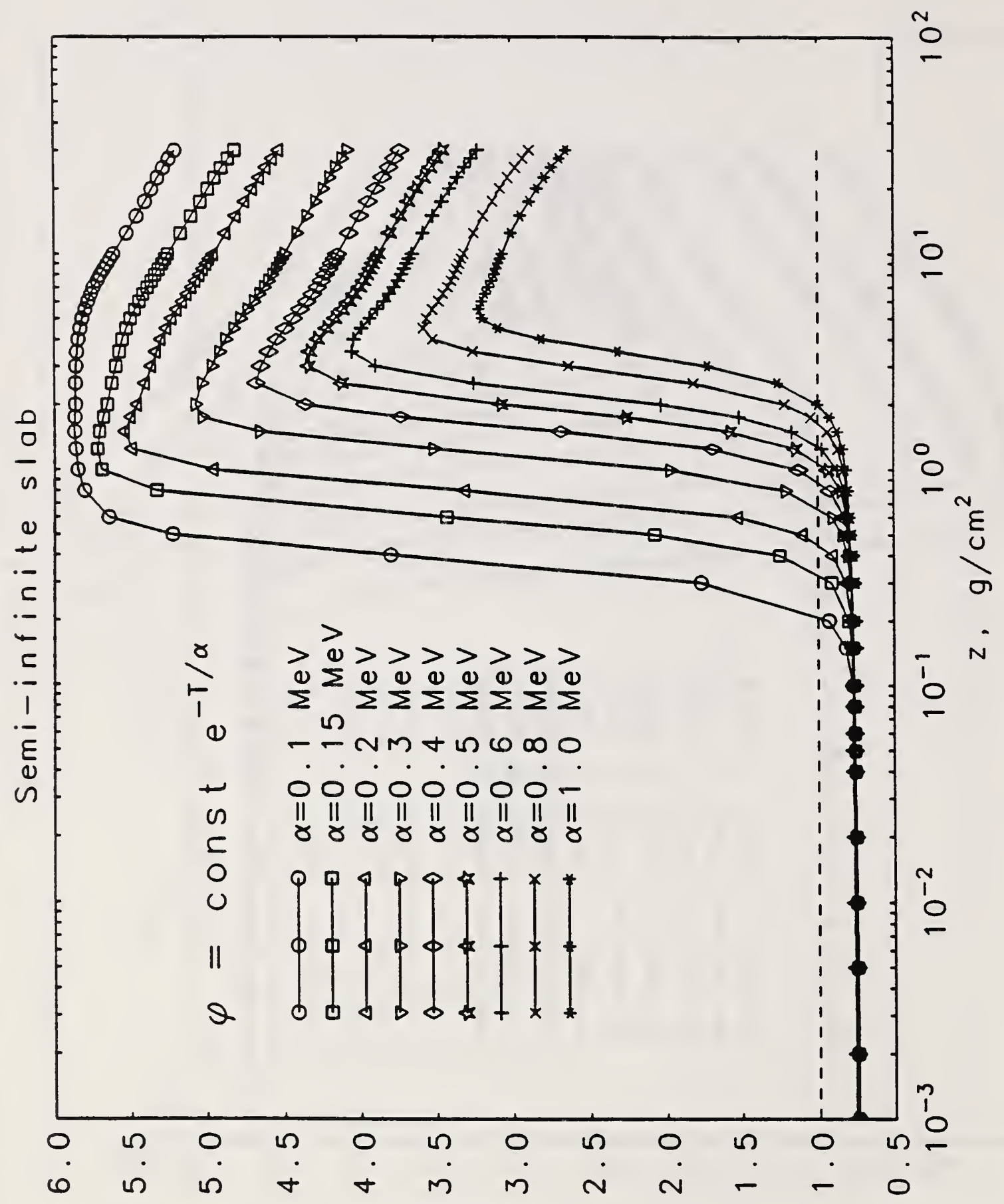

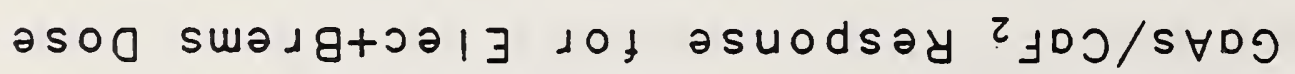




\section{Appendix A. Comments on Using SHIELDOSE-2}

The files supplied include those for SHIELDOSE-2: (a) SD2.FOR, the FORTRAN code; (b) PROTBAS2.DAT, the proton dose database; (c) ELBRBAS2.DAT, the electron and bremsstrahlung dose database; (d) SAMPLE.INP, sample input; and (e) SAMPLE.OUT, sample printout.

Also included is the DOSCON code to convert the SHIELDOSE-2 output to dose as a function of radius in a solid aluminum sphere and to dose at the inner surface of spherical aluminum shells. These files include: (a) DOSCON.FOR, the FORTRAN code; (b) SAMPLE.ARR, the array output from the sample run of SHIELDOSE-2; and (c) SAMPLE.CON, sample output of DOSCON.

\section{Program SHIELDOSE-2}

The functionality and flow of the present SHIELDOSE-2 code is nearly ident: $c$ al with the original SHIELDOSE code. The FORTRAN code has been compiled and run on a PC. With the dimensions chosen for the distribution file, it is necessary to use a system with a DOS extender to accommodate a $1.7 \mathrm{Mb}$ executable code (single precision). Comments in the code will guide you in converting to a double-precision version. A single-precision version that will fit cortably in the standard lower memory of a PC can be compiled by changing the value of NPT. rom 1001 to 251 in the parameter statements in the main program and in the subroutine SPECTR. This parameter governs the maximum choice for the number of integration points; we have found that a larger number tends to produce somewhat smoother (and more accurate) results, particularly for the proton dose at larger depths. Some further reduction can be done by reducing IMAXI from 71 to 51 in the parameter statements in the main program and in the subroutine SPHERE. This parameter governs the maximum choice for the number of depths at which the doses will be calculated.

The subroutine LOGO may require ANSI.SYS in your CONFIC.SYS to work correctly. The single call to it, near the start of the FORTRAN file, can easily be eliminated to avoid difficulties with your platform.

The input stream is nearly the same, and the user should consult reference [2] for general guidance. There are a few changes to the input parameters:

(1) Two initial records specify the destination of (a) the printout (tables) file, and (b) the file containing calculated 'nse arrays for possible subsequent analysis.

(2) The remaining input data is list-directed, and need not be in fixed columns but merely separated by appropriate delimiters (e.g., blanks or commas). It is important to know that for list-directed input, FORTRAN treats a blank as a delimiter, so that numbers entered in $\mathrm{E}$ format must not have a blank between the $\mathrm{E}$ and the exponent. E.g., $1.0 \times 10^{10}$ should be entered as $1.0 \mathrm{E}+10$, and not $1.00 \mathrm{E} 10$ which would be read as the two numbers 1.0 and 10.0 . 
(3) The first numerical input data record is IDET, INUC, IMAX, IUNT, where IDET is the selection among the detector materials, and INUC is the selection among the options to treat proton nuclear interactions. Selections for both parameters are listed early in the FORTRAN file.

(4) The remaining input parameters are the same as in the old code. In addition to allowing the specification of spectra exponential in energy, the new code also includes spectra exponential in rigidity. The key for these is for $\operatorname{EPS}(1)<=0$; then $S(1)$ is the efolding energy, $\mathrm{MeV}$ for exponential in energy and $\mathrm{MV}$ for exponential in rigidity, $\mathrm{S}(2)$ supplies the normalization for the spectrum, and $S(3)>0$ selects that the shape is exponential in rigidity rather than in energy. The normalization for these spectra is specified in a somewhat confusing manner, but the value for the integral under the spectrum is given in the printout.

(5) The new code still requires the selection of the energy grid limits for integration over the input spectra for the solar-proton, trapped-proton and electron components, as well as the number of energy points in the grid, that are separate from the actual incident spectral energies that can be read in. This facilitates the preparation of gridded arrays for each component that can be used repeatedly for calculations in different environments within a single run. Rather than using these limits regardless of the spectral energies read in (e.g., forcing dangerous cubic-spline extrapolation in some cases) as was done in the old code, the limits of integration are now set in the following way. For the component in question, let EMIN and EMAX be the selected energy limits, and let $\varepsilon_{j}$ be the monotonically increasing spectral energies that are read in. Then, the lower limit of integration for that spectrum is $\max \left[\mathrm{EMIN}, \varepsilon_{1}\right]$, and the upper limit is $\min \left[\mathrm{EMAX}, \varepsilon_{\mathrm{jmax}}\right]$. This insures that there is no extrapolation of the read-in spectra. For spectra chosen from analytical representations (exponential in energy or rigidity), EMIN and EMAX define the integration limits without modification. For read-in spectra, one should choose EMINs and EMAXs so as not to "waste" large portions of the gridded arrays.

\section{Program DOSCON}

The approximate transformations used to convert doses in slabs to those in solid spheres and at the inner surface of spherical shells, for radiation incident isotopically, are outlined in reference [3]. The code requests (1) the name of the SHIELDOSE-2 output array file, which may contain multiple calculations (for different environments), (2) the desired name for the output file, and (3) a value for the outer radius, which holds both for a solid aluminum sphere and for a spherical aluminum shell. In this essentially one-dimensional problem, all dimensions are specified in $\mathrm{g} / \mathrm{cm}^{2}$ of $\mathrm{Al}$ (actual length can be converted using a density for the aluminum, e.g., $2.7 \mathrm{~g} / \mathrm{cm}^{3}$ ).

The code automatically chooses the range of radii in the solid sphere and thicknesses of the shell that are accessible to the calculation. These ranges are largest when the SHIELDOSE calculation includes depths out to the maximum $50 \mathrm{~g} / \mathrm{cm}^{2}$ of aluminum. If no off-center radii in the solid sphere are accessible (i.e., the outer radius is too large), then solid-sphere results are not calculated at all. For large outer radii, the largest accessible shell thickness can be rather 
small. However, in the limit of infinite outer radius, the dose at the inner surface of the shell approaches twice that behind a plane slab of the same thickness. Therefore, supplemental shell thicknesses are added to cover thicknesses up to the outer radius, but only in the slab approximation. The automatic choices built into the present version of the code make it rather easy to use, but may not be optimum for every problem.

Please let me know of any difficulties, suggested changes, or needed improvements. This is a working version of the package that I did not want to hold back until further refined.

\author{
Stephen M. Seltzer \\ Ionizing Radiation Division \\ National Institute of Standards and Technology \\ Gaithersburg, MD 20899, USA \\ (301) 975-5552 \\ Fax: (301) 869-7682 \\ E-mail: seltzer@enh.nist.gov
}





\section{Appendix B. SHIELDOSE-2 Program Listing}

PROGRAM SD2

SHIELDOSE-2, VERSION 2.10, 28 APR 94.

S.M. SELTZER

NATIONAL INSTITUTE OF STANDARDS AND TECHNOLOGY

GAITHERSBURG, MD 20899

(301) $975-5552$

IDET $=1$, AL DETECTOR

2. GRAPHITE DETECTOR

3, SI DETECTOR

4. AIR DETECTOR

5, BONE DETECTOR

6. CALCIUM FLUORIDE DETECTOR

7. GALLIUM ARSENIDE DETECTOR

8. LITHIUM FLUORIDE DETECTOR

9. SILICON DIOXIDE DETECTOR

10, TISSUE DETECTOR

11. WATER DETECTOR

INUC $=1$, NO NUCLEAR ATTENUATION FOR PROTONS IN AL

2. NUCLEAR ATTENUATION, LOCAL CHARGED-SECONDARY ENERGY DEPOSITION

3. MUCLEAR ATTENUATION, LOCAL CHARGED-SECONDARY ENERGY DEPOSITION, AND APPROX EXPONENTIAL DISTRIBUTION OF NEUTRON DOSE

INCIDENT OMNIDIRECTIONAL FLUX IN /ENERGY/CMZ/UNIT TIME (SOLAR-FLARE FLUX IN /ENERGY/CM2).

EUNIT IS CONVERSION FACTOR FROM /ENERGY TO /MEV, E.G., EUNIT $=1000$ IF FLUX IS /KEV.

DURATN IS MISSION DURATION IN MULTIPLES OF UNIT TIME.

IMPLICIT DOUBLE PRECISION (A-H,O-Z)

PARAMETER (MMAXPI $=133$, KMAXPI $=30$, NMAXPI $=49$, LMAXPI $=51, I M I X I=11$,

1 MMAXEI $=81$, NMAXE I $=14$, LMAXSI $=33+1, L$ MAXE $I=51, L$ MAX $I=37, L M A X B I=47$,

$2 I \operatorname{MAXI}=71$, NPTSI $=1001, \mathrm{JMAXI}=301$ )

PARAMETER (NPTSPI $=$ NPTSI, NPTSE I $=$ NPTSI)

PARAMETER $\quad(Z C O N=0.001 \approx 2.540005 * 2.70, Z M C O N=10.0 / 2.70)$

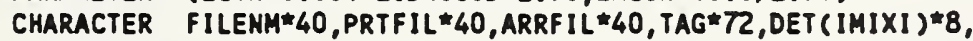

1 VERSION *4

DIMENSION EP(MMAXPI),RP(MMXXI),RPB(MMAXPI),RPC(MAXPI),

$1 \operatorname{RPO}($ MHAXPI), TEPN (KMAXPI), FEPN(KMAXPI), FEPNB (KMAXPI),

2 FEPNC(KMAXPI), FEPND (KMAXPI), TP (NMAXPI), ZRP (LMAXPI),

3 DUM (LMAXPI), DALP (NMAXP I , LMAXP I), DALPB (NMAXP I, LMAXPI),

4 DALPC (NMAXPI , LMAXPI), DALPO (MMAXPI , LMAXPI),

5 DRATP (NMAXPI, LMAXPI), DRATPB (NMAXPI, LMAXPI),

6 DRATPC (NMAXPI, LMAXPI), DRATPD (NMAXP I , LMAXPI)

DIMENSION EE (MMAXEI), RE (MMAXEI), REB (MMAXEI), REC (MMAXEI),

RED (MMAXEI), YE (MUAXEI), YEB (MHAXEI), YEC (MMAXEI), YED (MUAXEI),

2 TE (NMAXEI), AR (NMAXEI), ARB (NMAXEI), ARC (NMAXEI), ARD (NMAXE I),

3 RS(NMAXE I), RSB (NMAXEI), RSC (NMAXEI), RSD (NMAXEI), BS (LMAXSI),

4 ZRE (LMAXEI), ZS (LMAXTI), ZB (LMAXBI), DALE (NMAXEI, LMAXSI),

5 DALEB (NMAXE I, LMAXSI), DALEC (NMAXEI, LMAXSI), DALED (NMAXEI, LMAXSI),

6 DALB (NMAXEI , LMAXTI), DALBB (NMAXEI, LMAXTI), DALBC (NMAXEI, LMAXTI),

7 DALBD (MMAXEI , LMAXTI), DRATE (NMAXEI, LMAXEI , 2),

8 DRATEB (MMAXE I, LMAXE I , 2), DRATEC (MMAXE I, LMAXE I, 2),

9 DRATED (NMAXE I, LMAXE I, 2), DRATB (NMAXEI, LMAXBI, 2),

$X$ DRATBB (NMAXEI, LMAXBI, 2), DRATBC (NMAXEI, LMAXBI, 2),

1 DRATBD (NMAXEI, LMAXBI, 2)

DIMENSION ZM(IMAXI),Z(IMAXI), ZMM(IMAXI),ZL(IMAXI),TPL(NPTSPI), 


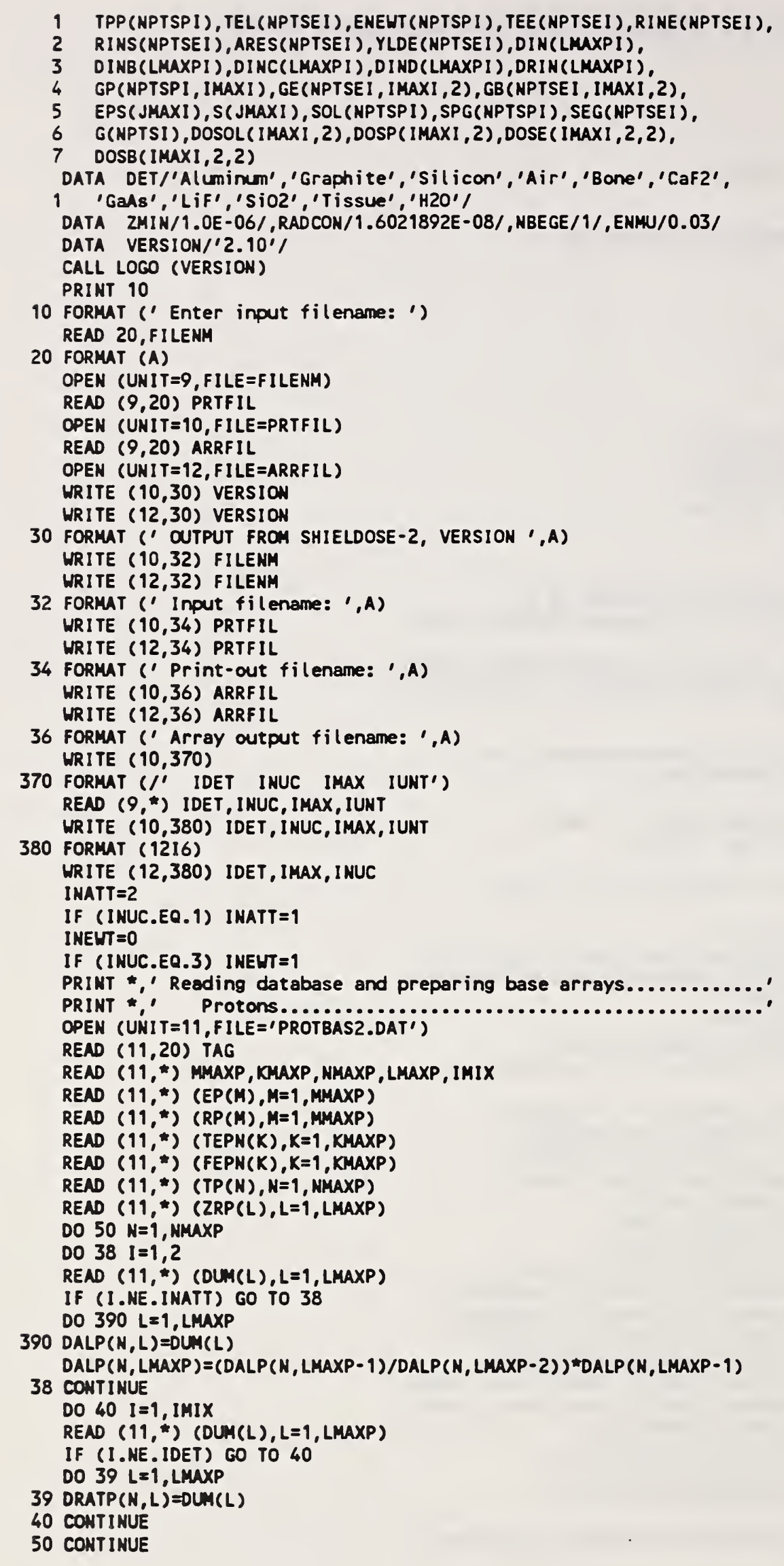


CLOSE (11)

DO $60 \mathrm{M}=1$, MMAXP

$\operatorname{EP}(M)=\operatorname{LOG}(E P(M))$

$60 \operatorname{RP}(M)=\operatorname{LOG}(R P(M))$

DO $65 K=1$, KMAXP

$65 \operatorname{TEPN}(K)=\operatorname{LOG}(\operatorname{TEPN}(K))$

DO $70 \mathrm{~N}=1$, NMAXP

$70 \operatorname{TP}(N)=\operatorname{LOG}(\operatorname{TP}(N))$

CALL SCOF (MMAXP,EP, RP, RPB, RPC, RPD)

CALL SCOF (KMAXP, TEPN, FEPN, FEPNB, FEPNC, FEPND)

DO $75 L=1$, L MAXP

DO $72 \mathrm{~N}=1$, NMAXP

$72 \operatorname{DALP}(N, L)=\operatorname{LOG}(D A L P(N, L))$

CALL SCOF (NMAXP,TP,DALP(1,L),DALPB $(1, L), \operatorname{DALPC}(1, L), \operatorname{DALPD}(1, L))$

75 CONTINUE

PRINT *, Electrons and bremsstrahlung...................'

OPEN (UNIT $=11$, FILE='ELBRBAS2.DAT')

READ $(11,20)$ TAG

READ $(11$, ,) MMAXE , NMAXE, LMAXS, LMAXE, LMAXT, LMAXB, IMIX

NLENE = NMAXE - NBEGE + 1

READ $(11, *)(E E(M), M=1, \operatorname{MMAXE})$

$\operatorname{READ}(11, *)$ (RE (M), M=1, MMAXE)

$\operatorname{READ}(11, *)$ (YE(M), $M=1$, MMAXE)

$\operatorname{READ}(11, *)$ (TE(N),N=1, NMAXE)

$\operatorname{READ}(11, *)(\operatorname{RR}(N), N=1, \operatorname{NMAXE})$

$\operatorname{READ}(11, \#)(\operatorname{RS}(N), N=1, \operatorname{NMAXE})$

READ $(11, *)$ (BS(L), L $=1$, LMAXS)

BS (LMAXS+1) $=2.0$

READ $(11, *)$ (ZRE $(L), L=1$, LMAXE)

$\operatorname{READ}(11, *)(Z S(L), L=1, L$ MAXT)

$\operatorname{REND}(11, \star) \quad(Z B(L), L=1, \operatorname{LMAXB})$

DO $100 N=1$, NMUXE

I) $0(19, \star)$ (DALE $(N, L), L=1$, LMAXS)

C. $E(N, L$ MAXS +1$)=1.0 E-07$

$\operatorname{READ}(11, \star)$ (DALB $(N, L), L=1, \operatorname{LMAXT})$

DO $90 \mathrm{I}=1$, IMIX

DO $80 \quad M=1,2$

READ $(19, \star)$ (DUM(L), L= 1 , LMAXE)

IF (I.NE.IDET) GO TO 77

DO 76 L=1, LMAXE

76 DRATE $(N, L, M)=D U M(L)$

77 READ $(11, *)$ (DUM(L),L=1, LMAXB)

IF (I.NE. IDET) GO TO 80

DO $78 L=1$, LMAXB

78 DRATB $(N, L, M)=D U M(L)$

80 CONTINUE

90 CONTINUE

100 CONTINUE

LMaXS $=$ LMAXS +1

CLOSE (11)

DO $110 M=1$, MMAXE

$E E(H)=\operatorname{LOG}(E E(M))$

$\operatorname{RE}(M)=\operatorname{LOG}(\operatorname{RE}(M))$

$110 \quad Y E(M)=L O G(Y E(M))$

DO $120 \mathrm{~N}=1$, NMAXE

$T E(N)=\operatorname{LOG}(T E(N))$

$\operatorname{AR}(N)=\operatorname{LOG}(A R(N))$

$120 \operatorname{RS}(N)=\operatorname{LOG}(\operatorname{RS}(N))$

DO $130 L=1, L$ MAXB

$130 \mathrm{ZB}(L)=\operatorname{LOG}(Z B(L))$

CALL SCOF (MMAXE,EE, RE, REB, REC, RED)

CALL SCOF (MMXX,EE, YE, YEB, YEC, YED)

CALL SCOF (NMAXE, TE, AR, ARB, ARC, ARD)

CALL SCOF (NMUXE,TE,RS,RSB,RSC,RSD)

DO 150 L=1, LMAXS

DO $140 \mathrm{~N}=$ NBEGE, NMAXE

$140 \operatorname{DALE}(N, L)=\operatorname{LOG}(\operatorname{DALE}(N, L))$

CALL LCOF (NLENE, TE (NBEGE), DALE (NBEGE,L), DALEB (NBEGE,L),

1 DALEC (NBEGE, L), DALED (NBEGE, L )) 


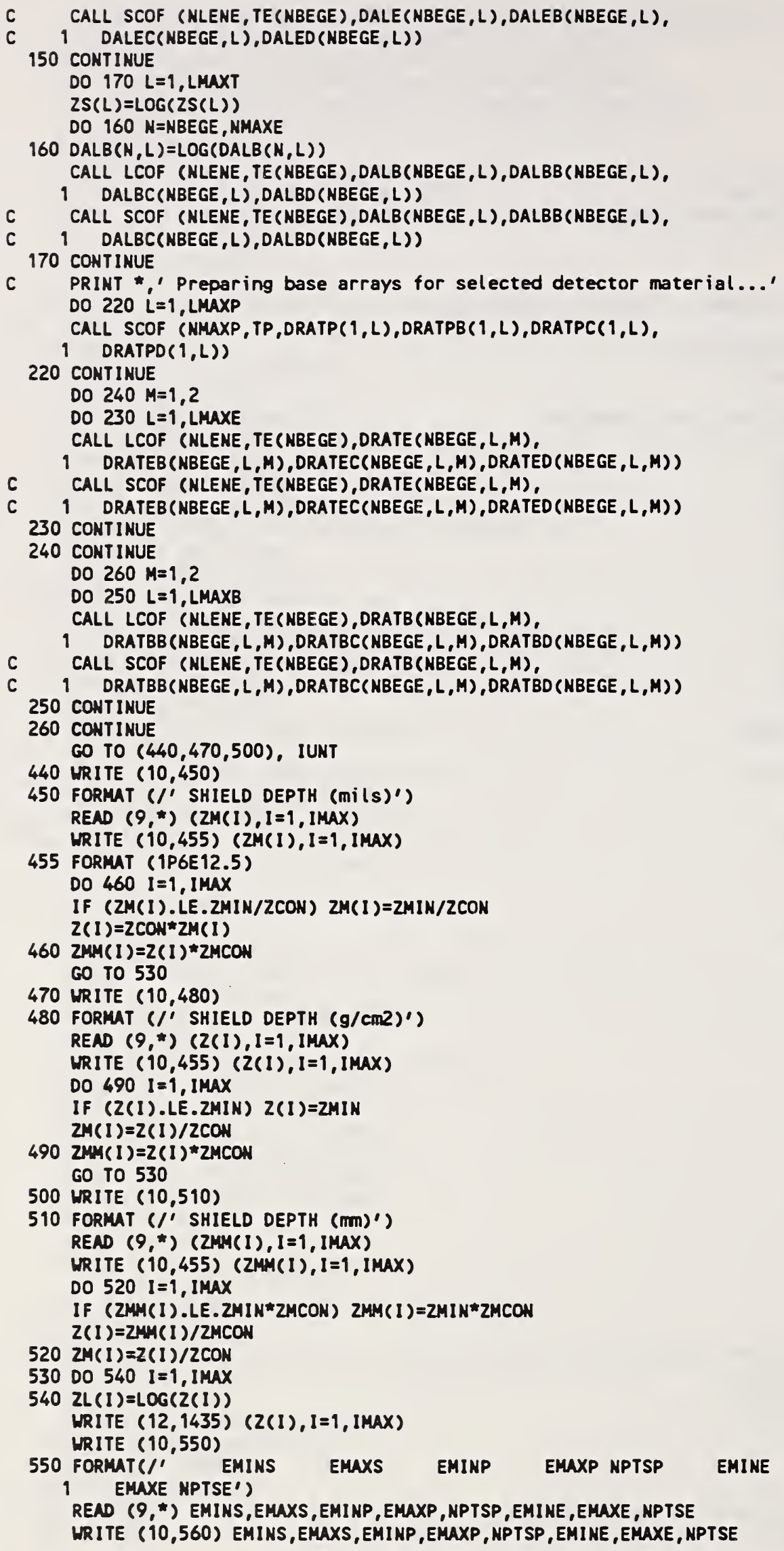


560 FORMAT $(4 F 10.3,16,2 F 10.3,16)$

EMINU $=$ HIN(EMINP, EMINS)

EMAXU $=$ MAX (EMAXP,EMUXS)

DEP =LOG (EMAXU/EMINU) /FLOAT (NPTSP-1)

EMINUL $=\operatorname{LOG}(E M I N U)$

$D E L P=D E P / 3.0$

CALL EINDEX (EMINU, DEP, NPTSP, EMINS, EMAXS, NFSTSB, NLSTSB, NLENSB)

CALL EINDEX (EMINU, DEP, NPTSP, EMINP , EMAXP, NFSTPB , NLSTPB, NLENPB)

DO 570 NP $=1$, NPTSP

$T P L(N P)=E M I N U L+F L O A T(N P-1) * D E P$

$\operatorname{TPP}(N P)=\operatorname{EXP}(T P L(N P))$

570 CONTINUE

WR I TE $(10,580)$ TPP (NFSTSB), TPP (NLSTSB), TPP (NFSTPB), TPP (NLSTPB),

1 NPTSP, EMINE, EMAXE, NPTSE

580 FORMAT (4F10.3,16,2F10.3,16,' ADJUSTED VALUES')

WRITE (12,560) TPP (NFSTSB), TPP (NLSTSB), TPP (NFSTPB), TPP (NLSTPB),

1 NPTSP, EMINE, EMAXE, NPTSE

PRINT *' Preparing mesh arrays to be integrated over spectra....'

PRINT *, Protons....................................'

DO 660 NP $=1$, NPTSP

CALL BSPOL (TPL (NP), MMAXP, EP, RP, RPB , RPC, RPD, ANS)

RINP $=$ EXP (ANS)

DO 610 L=1, LMAXP

IF (TPL(NP).LT.TP (NMAXP)) GO TO 590

ANS $=D A L P($ NMAXP, L)

ANSR $=$ DRATP $($ NMAXP,$L)$

GO TO 605

590 IF (TPL(NP).GT.TP(1)) GO TO 600

ANS $=D A L P(1, L)$

$\operatorname{ANSR}=D \operatorname{RATP}(1, L)$

GO TO 605

600 CALL BSPOL (TPL (NP), MMAXP,TP,DALP $(1, L), D A L P B(1, L)$,

$1 \operatorname{DALPC}(1, L), \operatorname{DALPO}(1, L), A N S)$

ANSR $=1.0$

IF (IDET.EQ.1) GO TO 605

CALL BSPOL (TPL (NP), NMAXP,TP,DRATP $(1, L), \operatorname{DRATPB}(1, L)$,

$1 \operatorname{DRATPC}(1, L), \operatorname{DRATPD}(1, L), A N S R)$

605 DIN(L) $=$ ANS 4 IOG (ANSR)

610 CONTINUE

ENEUT (NP) $=0.0$

BENMU $=0.0$

IF (INATT.EQ.1) GO TO 620

IF (TPL(NP).LE.TEPN(1)) GO TO 615

CALL BSPOL (TPL (NP), KMAXP, TEPN, FEPN, FEPNB, FEPNC, FEPND, ANS)

ENEUT (NP) $=T P P(N P)$ *ANS

615 BENMU =ENEWT (NP) ॠENMU

620 CALL SCOF (LMAXP, ZRP, DIN, DINB, DINC, DIND)

DO $650 \quad I=1$, I MAX

ZRIN=Z(1)/RINP

IF (ZRIN.LT.ZRP(LMAXP)) GO TO 640

$\operatorname{GP}(N P, 1)=0.0$

GO TO 645

640 CALL BSPOL (ZRIN, LMAXP, ZRP, DIN,DINB, DINC, DIND, ANS)

ANS $=\operatorname{EXP}($ ANS )

$\operatorname{GP}(N P, I)=T P P(N P) \star A N S / R I N P$

645 IF (INEWT.EQ 1 . AND.TPL (NP). GT . TEPN(1)) $\operatorname{GP}(N P, 1)=G P(N P, 1)+$

1 BENMUःEXP(-ENMUःZ(1))

650 CONTINUE

660 CONTINUE

PRINT *' Electrons and brensstrahlung..................'

EMINEL $=$ LOG (EMINE)

DEE $=($ LOG (EMAXE) - EMINEL )/FLOAT (NPTSE-1)

$D E L E=D E E / 3.0$

DO 670 NE $=1$, NPTSE

TEL (NE) $=E M I N E L+F L O A T(N E-1) * D E E$

$\operatorname{TEE}(N E)=\operatorname{EXP}(T E L$ (NE) )

CALL BSPOL (TEL (NE), MMAXE, EE, RE, REB, REC, RED, ANS)

$\operatorname{RINE}(N E)=\operatorname{EXP}$ (ANS)

CALL BSPOL (TEL ( $N E)$, MMAXE, TE, RS, RSB, RSC, RSD, ANS) 
RINS (NE) $=R$ INE (NE) $\# E X P$ (ANS)

CALL BSPOL (TEL (NE), NMAXE, TE, AR, ARB , ARC, ARD , ANS)

ARES (NE) $=$ EXP (ANS)

CALL BSPOL (TEL (NE), MHAXE, EE, YE, YEB, YEC, YED, ANS)

$670 \mathrm{YLDE}($ NE) $=$ EXP (ANS)

DO $820 \quad M=1,2$

DO 815 NE=1, NPTSE

DO 700 L $=1$, LMAXS

IF (TEL(NE).LT.TE(NMXE)) GO TO 680

$\operatorname{DIN}(L)=D A L E(N M A X E, L)$

GO TO 700

680 IF (TEL(NE).GT.TE(NBEGE)) GO TO 690

$\operatorname{DIN}(L)=D A L E(N B E G E, L)$

GO TO 700

690 CALL BSPOL (TEL (NE), NLENE, TE (NBEGE),DALE (NBEGE,L), DALEB (NBEGE,L), 1 DALEC(NBEGE,L),DALED (NBEGE,L),DIN(L))

700 CONTINUE

DO $715 L=1$, LMAXE

$\operatorname{DRIN}(L)=1.0$

IF (IDET.EQ.1.AND.M.EQ.1) GO TO 715

IF (TEL(NE).LT.TE(NMAXE)) GO TO 710

DRIN $(L)=D R A T E$ (NMAXE, $L, M)$ GO TO 715

710 If (TEL(NE).GT.TE(NBEGE)) GO TO 712 DRIN(L) $=$ DRATE (NBEGE, $L, M)$

GO TO 715

712 CALL BSPOL (TEL(NE), NLENE, TE (NBEGE),DRATE (NBEGE, L,M),

1 DRATEB (NBEGE, $L, M)$, DRATEC(NBEGE, L, M), DRATED (NBEGE, $L, M), D R I N(L))$ IF (DRIN(L).LT.0.0) DRIN(L) $=0.0$

715 CONTINUE

C CALL LCOF (LMAXS,BS,DIN,DINB,DINC,DIND)

CALL SCOF (LMAXS,BS,DIN,DINB,DINC,DIND)

DO $740 I=1, I$ MAX

ZRIN=Z(I)/RINS(NE)

IF (ZRIN.LT.BS(LMAXS)) GO TO 730

$720 \mathrm{GE}(N E, I, M)=0.0$

GO TO 740

730 CALL BSPOL (ZRIN, LMAXS,BS,DIN,DINB,DINC,DIND, ANS)

ANS $=E X P$ (ANS)

GE (NE, $\perp, M)=$ TEE (NE) *ANS*ARES (NE)/RINS (NE)

740 CONTINUE

C CALL LCOF (LMAXE, ZRE,DRIN,DINB,DINC,DIND)

CALL SCOF (LMAXE, ZRE,DRIN,DINB,DINC,DIND)

DO $745 I=1$, I MAX

ZRIN=Z(I)/RINE (NE)

IF (ZRIN.LT.ZRE(LMAXE)) GO TO 742

GE (NE, I, M) $=$ GE (NE, I, M)*DRIN (LMAXE)

GO TO 745

742 CALL BSPOL (ZRIN, LMAXE, ZRE,DRIN,DINB,DINC,DIND, ANSR)

If (ANSR.LT.0.0) ANSR $=0.0$

$G E(N E, 1, M)=G E(N E, 1, M){ }^{\star} A N S R$

745 CONTINUE

DO $780 L=1$, LMAXT

IF (TEL(NE).LT.TE(NMAXE)) GO TO 760

$\operatorname{DIN}(L)=D A L B$ (NMAXE, L)

GO TO 780

760 IF (TEL(NE).GT.TE(NBEGE)) GO TO 770

$D I N(L)=D A L B(N B E G E, L)$

GO TO 780

$770 \mathrm{CALL} B S P O L$ (TEL (NE), NLENE, TE (NBEGE), DALB (NBEGE,L),DALBB (NBEGE,L),

1 DALBC(NBEGE, L),DALBD(NBEGE,L),DIN(L))

780 CONTINUE

DO $795 \quad L=1$, LMAXB

DRIN $L)=1.0$

IF (IDET.EQ.1.AND.M.EQ.1) GO TO 795

IF (TEL(NE).LT.TE(NMAXE)) GO TO 790

DRIN(L) $\Rightarrow$ DRATB (NMAXE, L,M)

GO TO 795

790 IF (TEL(NE).GT.TE(NBEGE)) GO TO 792 
$\operatorname{DRIN}(L)=D R A T B(N B E G E, L, H)$

GO TO 795

792 CALL BSPOL (TEL (NE), NLENE, TE (NBEGE), DRATB (NBEGE, L, M)

1 DRATBB (NBEGE, $L, M), \operatorname{DRATBC}(N B E G E, L, M), D R A T B D(N B E G E, L, M), D R I N(L))$

If $(\operatorname{DRIN}(L) . L T .0 .0)$ DRIN(L) $=0.0$

795 CONTINUE

CALL LCOF (LMAXT,ZS,DIN,DINB,DINC,DIND)

C CALL SCOF (LMAXT,ZS,DIN,DINB,DINC,DIND)

DO $800 \quad I=1$, IMAX

$Z R I N L=\operatorname{LOG}(Z(1) / R I N E(N E))$

CALL BSPOL (ZRINL, LMAXT, ZS, DIN,DINB, DINC, DIND, ANS)

ANS $=\operatorname{EXP}$ (ANS)

$G B(N E, 1, M)=T E E(N E) \star A N S * Y L D E(N E) / R I N E(N E)$

800 CONTINUE

CALL LCOF (LMAXB, ZB,DRIN,DINB,DINC,DIND)

c.

CALL SCOF (LMAXB,ZB,DRIN,DINB,DINC,DIND)

DO $812 I=1, I$ MAX

IF (ZL(1).LT.ZB(LMAXB)) GO TO 810

$\mathrm{GB}(N E, I, M)=\mathrm{GB}(\mathrm{NE}, I, M) \star D R I N(L$ MAXB $)$

GO TO 812

810 CALL BSPOL (ZL (1), LMAXB, ZB, DRIN, DINB, DINC, DIND , ANSR)

IF (ANSR.LT.O.O) ANSR $=0.0$

$G B(N E, I, M)=G B(N E, I, M) \star A N S R$

812 CONTINUE

815 CONTINUE

820 CONTINUE

PRINT *,' Performing calculations for input spectra............'

830 WRITE $(10,840)$

840 FORMAT $(/)$

WRITE $(10,850)$

850 FORMAT ( $(1$,

READ $(9,20, E N D=1440)$ TAG

PRINT 860, TAG

860 FORMAT $(4 \dot{X}, A)$

WRITE $(10,20)$ TAG

WRITE $(12,20)$ TAG

WRITE $(10,870)$

870 FORMAT ( $/$ ' JSMAX JPMAX JEMAX EUNIT DURATN')

READ $(9, *)$ JSMAX, JPMAX, JEMAX, EUNIT, DURATH

URITE $(10,880)$ JSMAX, JPMAX, JEMAX, EUNIT, DURATH

WRITE $(12,880)$ JSMAX, JPMAX, JEMAX, EUNIT, DURATN

880 FORMAT $(316,1$ 1PE12.5)

IF (DURATN.LE.0.0) DURATH $=1.0$

DELTAS $=$ RADCON*DELP $/ 4.0$

DELTAP $\Rightarrow$ DURATN*RADCON*DELP $/ 4.0$

DELTAE =DURATN*RADCON*DELE/4.0

IF (EUNIT.LE.0.0) EUNIT $=1.0$

I $\mathrm{SOL}=2$

If (JSMAX.LT.3) 60 TO 900

I SOL $=1$

URITE $(10,885)$

885 FORMAT (//'E(MeV)')

$\operatorname{REND}(9, \star)(\operatorname{EPS}(J), j=1, J \operatorname{SHAX})$

WRITE $(10,905)$ (EPS $(J), J=1, J \operatorname{SMAX})$

WRITE $(12,905)$ (EPS (J),J=1,JSMAX)

WRITE $(10,890)$

890 FORHAT ( $/$ ' SOLAR PROTOW SPECTRUM (/energY/cm2)')

$\operatorname{REND}(9, \star)(S(J), J=1, J$ SMAX)

WRITE $(10,905)(S(J), J=1, J S M A X)$

WRITE $(12,905)(S(J), J=1, J$ SMAX)

NLENS=NLENSB

NFSTS $=$ NFSTSB

NLSTS $=$ NLSTSB

CALL SPECTR ( JSMUX, EPS, S, EUNIT, EMINU, DEP, NPTSP, NFSTS, NLSTS, NLENS, 1 TPP, TPL, SOL)

WRITE (10,891) TPP(NFSTS), TPP(NLSTS), NLENS

891 FORMAT (/' SPECTRUM INTEGRATED FROM', IPE11.4,' TO', IPE11.4,

1 ' MeV, USING', 15,' POINTS')

DO 892 NP=NFSTS, NLSTS 
$892 G(N P)=S O L(N P) \star E N E W T(N P)$

CALL INTEG (DELP, G(NFSTS), NLENS, ENEUT)

DO 894 NP=NFSTS, NLSTS

$894 \mathrm{G}($ NP) $=$ SOL (NP) *TPP (NP)

CALL INTEG (DELP, G(NFSTS), NLENS, EAV)

ENEUT $=$ ENEUT /EAV

WRITE $(10,896)$ ENEUT

896 FORMAT ( $/$ ' ASSUMED FRACTION OF BEAM ENERGY INTO NEUTRON ENERGY =', 1 IPE12.5)

900 ITRP $=2$

IF (JPMAX.LT.3) GO TO 920

ITRP $=1$

WRITE $(10,885)$

$\operatorname{READ}(9, \star)(\operatorname{EPS}(J), J=1, J P M A X)$

WRITE $(10,905)$ (EPS $(J), J=1, J P M A X)$

WRITE $(12,905)$ (EPS(J), J=1, JPMAX)

905 FORMAT (IP1OE12.4)

URITE $(10,910)$

910 FORMAT (/' TRAPPED PROTON SPECTRUM (/energy/cm2/time)')

READ $(9, \star)(S(J), J=1, J P M A X)$

WRITE $(10,905)(S(J), J=1, J P M A X)$

WRITE $(12,905)(S(J), J=1$, JPMAX)

NLENP $=$ NLENPB

NFSTP $=$ NFSTPB

NLSTP $=N L S T P B$

CALL SPECTR ( JPMAX, EPS, S, EUNIT, EMINU, DEP, NPTSP, NFSTP, NLSTP, NLENP, 1 TPP, TPL, SPG)

WRITE $(10,891)$ TPP (NFSTP), TPP (NLSTP), NLENP

DO 912 NP=NFSTP, NLSTP

$912 G(N P)=S P G(N P) \star E N E W T(N P)$

CALL INTEG (DELP,G(NFSTP), NLENP, ENEUT)

DO 914 NP=NFSTP, NL.STP

$914 G(N P)=S P G(N P) \approx T P P(N P)$

CALL INTEG (DELP, G(NFSTP), NLENP, EAV)

ENEUT $=E N E U T / E A V$

WRITE $(10,896)$ ENEUT

920 ILEC $=2$

IF (JEMAX.LT.3) GO TO 940

ILEC $=1$

WRITE $(10,885)$

READ $(9, *)$ (EPS $(J), J=1$, JEMAX)

WRITE $(10,905)$ (EPS $(J), J=1$, JEMAX)

WRITE $(12,905)$ (EPS $(J), J=1, J E M A X)$

WRITE $(10,930)$

930 FORMAT (/' ELECTRON SPECTRUM (/energy/cm2/time)')

READ $(9, \star)(S(J), J=1, J E M A X)$

URITE $(10,905)(S(J), J=1, J E M A X)$

HRITE $(12,905)(S(J), J=1$, JEMAX)

NLENE $=$ NPTSE

NFSTE $=1$

NLSTE=NPTSE

CALL SPECTR (JEMAX, EPS, S, EUNIT, EMINE, DEE, NPTSE, NFSTE, NLSTE, NLENE, 1 TEE, TEL, SEG)

WRITE (10,891) TEE(NFSTE), TEE(NLSTE), NLENE

940 CO TO $(980,950)$, ISOL

950 DO 960 NP=NFSTS, NLSTS

$960 \mathrm{SOL}(\mathrm{NP})=0.0$

DO $970 \mathrm{~J}=1,2$

DO $970 \quad I=1, I$ max

$970 \operatorname{DOSOL}(1, J)=0.0$

CO TO 1010

980 DO $1000 \quad 1=1$, I MAX

DO 990 NP=NFSTS, NLSTS

$990 \mathrm{G}(\mathrm{NP})=\mathrm{SOL}(\mathrm{NP}) \star \mathrm{GP}(\mathrm{NP}, 1)$

CALL INTEG (DELTAS, G(NFSTS), NLENS,DOSOL $(1,1)$ )

1000 CONTINUE

CALL SPHERE (ZL,DOSOL $(1,1), I M A X, \operatorname{DOSOL}(1,2)$ )

1010 CO TO $(1050,1020)$, ITRP

1020 DO 1030 NP=NFSTP, NLSTP 
$1030 \operatorname{SPG}(N P)=0.0$

DO $1040 \mathrm{~J}=1,2$

DO $1040 \quad 1=1,1$ max

$1040 \operatorname{DOSP}(1, J)=0.0$

GO TO 1080

1050 DO $1070 \quad I=1$, IMAX

DO 1060 NP=NFSTP, NLSTP

$1060 \mathrm{G}(\mathrm{NP})=\mathrm{SPG}(\mathrm{NP}) * \mathrm{GP}(\mathrm{NP}, 1)$

CALL INTEG (DELTAP,G(NFSTP), NLENP,DOSP( 1,1$)$ )

1070 CONTINUE

CALL SPHERE (ZL,DOSP(1,1), IMAX,DOSP $(1,2))$

1080 GO TO $(1110,1090)$, ILEC

1090 DO $1100 \mathrm{~J}=1,2$

DO $1100 \quad M=1,2$

DO $1100 \quad I=1,1$ MAX

$\operatorname{DOSE}(1, M, J)=0.0$

$1100 \operatorname{DOSB}(1, M, J)=0.0$

GO TO 1160

1110 DO $1150 \quad M=1,2$

DO $1130 \quad I=1$, IMAX

DO 1120 NE=NFSTE, NLSTE

$G(N E)=S E G(N E) * G E(N E, 1, M)$

1120 SPG(NE) $=S E G(N E) \star G B(N E, 1, M)$

CALL INTEG (DELTAE, G(NFSTE), NLENE, DOSE $(1, M, 1)$ )

CALL INTEG (DELTAE, SPG(NFSTE), NLENE,DOSB $(1, M, 1)$ )

1130 CONT INUE

GO TO $(1140,1150)$, M

1140 CALL SPHERE $(Z L, \operatorname{DOSE}(1, M, 1), \operatorname{IMAX}, \operatorname{DOSE}(1, M, 2))$

CALL SPHERE (ZL,DOSB $(1, M, 1), I M A X, D O S B(1, M, 2))$

1150 CONTINUE

$1160 \mathrm{~J}=1$

DO $1340 M=2,1,-1$

GO TO $(1190,1170)$, M

1170 WRITE $(10,1180)$

1180 FORMAT (//' DOSE AT TRANSMISSION SURFACE OF FINITE ALUMINUM SLAB SH 11 IELDS')

GO TO 1210

1190 WRITE $(10,1200)$

120R FORMAT(//' DOSE IN SEMI-INFINITE ALUMINUM MEDIUM')

121 WRITE $(10,1230)$ DET (IDET)

1230 FORMAT ( $/$ ' rads ',A)

IF (INATT.EO.1) WRITE $(10,1240)$

1240 FORMAT (/'Proton results without nuclear attenuation')

IF (INATT.EO.2) WRITE $(10,1250)$

1250 FORMAT (/'Proton results with approximate treatment of nuclear at 1 tenuation's

IF (INATT.EQ.2.AND.INEWT.EQ.0) WRITE $(10,1260)$

1260 FORMAT (' neglecting transport of energy by neutrons')

IF (INATT.EO.2.AND.INEWT.EQ.1) WRITE $(10,1270)$

1270 FORMAT ( ' and crude exponential transport of energy by neutron (s')

URITE $(10,1310)$

1310 FORMAT( $/ 12$ (mils) $z(\mathrm{~mm}) \quad z(\mathrm{~g} / \mathrm{cm} 2)$ ELECTRON BREMS

1 EL+BR TRP PROT SOL PROT EL+BR+TRP TOTAL')

WRITE $(10,850)$

DO $1330 \quad l=1, \mathrm{I} M A X$

$\operatorname{DOSEB}=\operatorname{DOSE}(I, M, J)+\operatorname{DOSB}(I, M, J)$

DOSEBP $=D O S E B+D O S P(l, J)$

DOST $\Rightarrow$ DOSEBP $+D O S O L(1, J)$

WRITE $(10,1320) Z M(1), Z M M(1), Z(1), D O S E(1, M, J), D O S B(I, M, J), D O S E B$,

$1 \operatorname{DOSP}(1, J), D O S O L(1, J), D O S E B P, D O S T$

1320 FORMAT (IPIOE11.3)

IF (FLOAT $(1 / 10) \cdot$ EQ.0.1*FLOAT(I)) WRITE $(10,850)$

1330 CONTINUE

1340 CONTINUE

$J=2$

$M=1$

WRITE $(10,1350)$

1350 FORMAT (//' $1 / 2$ DOSE AT CENTER OF ALUMINUM SPHERES') 


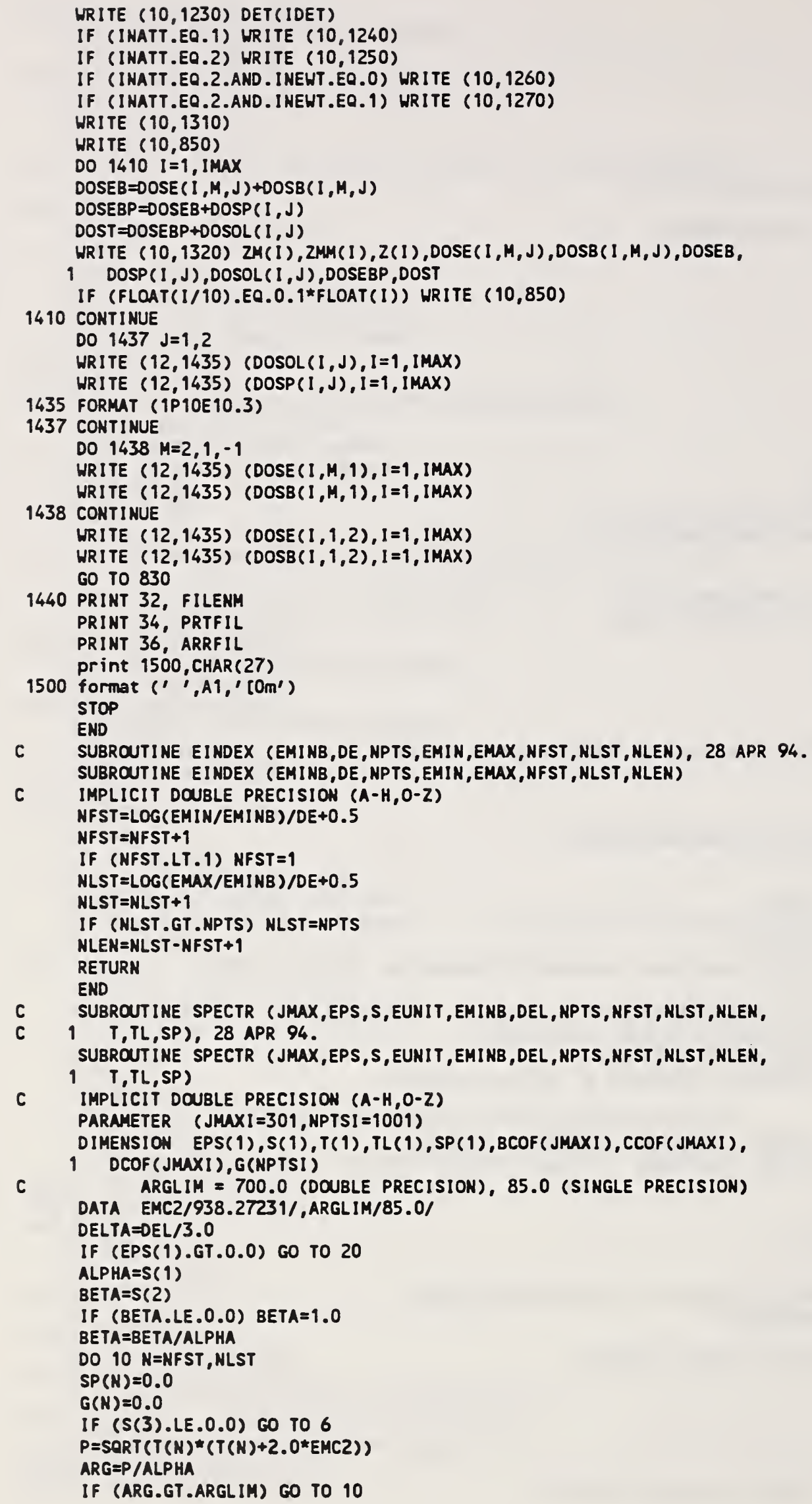


$S P(N)=T(N) * B E T A *((T(N)+E M C 2) / P) * E X P(-A R G)$

GO TO 8

6 ARG $=T(N) / A L P H A$

IF (ARG.GT.ARGLIM) GO TO 10

$\operatorname{SP}(N)=T(N) * B E T A * E X P(-A R G)$

$8 G(N)=T(N) \star S P(N)$

10 CONTINUE

GO TO 50

20 CALL EINDEX (EMINB, DEL, NPTS, EPS (1), EPS (JMAX), NFST, NLST, NLEN)

DO $30 \mathrm{~J}=1$, JMAX

$\operatorname{EPS}(J)=\operatorname{LOG}(\operatorname{EPS}(J))$

$30 S(J)=\operatorname{LOG}\left(E U N I T^{\star} S(J)\right)$

CALL SCOF (JMAX, EPS, S, BCOF, CCOF,DCOF)

DO $40 \mathrm{~N}=\mathrm{NFST}, \mathrm{NLST}$

CALL BSPOL (TL (N), JMAX, EPS, S, BCOF, CCOF, DCOF, ANS)

$\operatorname{SP}(N)=T(N)=\operatorname{EXP}(A N S)$

$40 G(N)=T(N)=S P(N)$

50 CALL INTEG (DELTA, SP(NFST), NLEN, SIN)

CALL INTEG (DELTA, G(NFST), NLEN, EBAR)

$E B A R=E B A R / S I N$

URITE $(10,60)$

60 FORMAT ( $/ '$ INT SPEC EAV(MeV)')

WRITE $(10,70)$ SIN, EBAR

70 FORMAT (1PE12.4, OPF12.5)

RETURN

C

$$
\text { END }
$$

SUBROUTINE SPHERE (ZL,DOSE, IMAX,DOSPH), 26 JAN 93.

SUBROUTINE SPHERE (ZL,DOSE, IMAX,DOSPH)

IMPLICIT DOUBLE PRECISION $(A-H, O-Z)$

PARAMETER (IMAXI $=71$ )

DIMENSION ZL(1),DOSE(1),DOSPH(1),DOSL (IMAXI), BCOF (IMAXI),

$1 \operatorname{CCOF}(I \operatorname{MAXI})$, DCOF (IMAXI)

DO $10 \mathrm{I}=1,1 \mathrm{I}$ MAX

IF (DOSE(I).LE.0.0) GO TO 20

$10 \operatorname{DOSL}(I)=\operatorname{LOG}(\operatorname{DOSE}(I))$

$I=I$ MAX +1

20 I $\operatorname{IIX}=I-1$

IF (IMIX.LT.3) GO TO 40

CALL SCOF (IMIX, ZL,DOSL,BCOF, CCOF,DCOF)

$B C O F(I M I X)=B \operatorname{COF}(I M I X-1)+\left(2.0^{*} \operatorname{CCOF}(I M I X-1)+3.0^{*} D C O F(I M I X-1) *\right.$

$1(Z L(I M I X)-Z L(I M I X-1))) *(Z L(I M I X)-Z L(I M I X-1))$

DO $30 \quad I=1$, IMIX

$30 \operatorname{DOSPH}(1)=\operatorname{DOSE}(1) *(1.0-8 \operatorname{COF}(1))$

40 IMIXI $=$ IMIX+1

IF (IMIX1.GT.IMAX) RETURN

DO 50 I $=I M I X 1, I$ MAX

$50 \operatorname{DOSPH}(1)=0.0$

RETURN

END

SUBROUT INE $S C O F(N, X, Y, B, C, D)$

REINSCH ALGORITHM, VIA MJB, 22 FEB 83

$Y(S)=((D(J) *(X-X(J))+C(J)) *(X-X(J))+B(J)) *(X-X(J))+Y(J)$ FOR $X$ BETUEEN $X(J)$ AND $X(J+1)$

IMPLICIT DOUBLE PRECISION $(A-H, O-Z)$

DIMENSION $X(1), Y(1), B(1), C(1), D(1)$

$N 1=N-1$

$S=0.0$

DO $10 \mathrm{~J}=1, \mathrm{~N} 1$

$D(J)=x(J+1)-x(J)$

$R=(Y(J+1)-Y(J)) / D(J)$

$C(f)=R-2$

$10 \mathrm{~S}=\mathrm{R}$

$S=0.0$

$R=0.0$

$C(1)=0.0$

$C(N)=0.0$

DO $20 \mathrm{~J}=2, \mathrm{~N} 1$

$C(J)=C(J)+R * C(J-1)$

$B(J)=(X(J-1)-X(J+1)) * 2.0-R * S$ 
$S=D(J)$

$20 R=S / B(J)$

DO $30 \mathrm{JR}=\mathrm{N1}, 2,-1$

$30 C(J R)=(D(J R) * C(J R+1)-C(J R)) / B(J R)$

DO $40 \mathrm{~J}=1, \mathrm{~N} 1$

$S=D(J)$

$R=C(J+1)-C(J)$

$D(J)=R / S$

$C(J)=3.0 * C(J)$

$40 B(J)=(Y(J+1)-Y(J)) / S-(C(J)+R) * S$

RETURN

END

SUBROUTINE BSPOL $(S, N, X, Y, B, C, D, T)$

BINARY SEARCH, $X$ ASCENDING OR DESCENDING

C IMPLICIT DOUBLE PRECISION $(A-H, O-Z)$

DIMENSION $X(1), Y(1), B(1), C(1), D(1)$

IF $(X(1) . G T . X(N))$ GO TO 10

IDIR $=0$

$M L B=0$

MUB $=\mathrm{N}$

GO TO 20

10 IDIR $=1$

$M L B=N$

MUB $=0$

20 IDIRI=IDIR-1

IF (S.GE.X(MUB+IDIR)) GO TO 60

IF (S.LE.X(MLB-IDIR1)) GO TO 70

$M L \#$ MLB

$M U=M U B$

GO TO 40

30 IF (IABS(MU-ML).LE.1) GO TO 80

40 MAV $=(M L+M U) / 2$

If (S.LT.X(MAV)) GO TO 50

$M L=$ LAV

GO TO 30

$50 \mathrm{MU}=$ MAV

GO TO 30

$60 M U=\# U B+I D I R+I D I R 1$

GO TO 90

$70 M U=M L B-1 D I R-I D I R 1$

GO TO 90

$80 \mathrm{MU}=\mathrm{MU}+10 \mathrm{IR} 1$

$90 Q=S-X$ (MU)

$T=((D(M U) * Q+C(M U)) * Q+B(M U)) * Q+Y(M U)$

RETURN

END

SUBROUTINE LCOF (NMAX, X,F,B,C,D)

C 26 JAN 93. SIMPLE LINEAR INTERPOLATION

C IMPLICIT DOUBLE PRECISION $(A-H, O-Z)$

DIMENSION $X(1), F(1), B(1), C(1), D(1)$

DO $10 N=1, N M A X-1$

$B(N)=(F(N+1)-F(N)) /(X(N+1)-X(N))$

$C(N)=0.0$

$D(N)=0.0$

10 CONTINUE

RETURN

END

SUBROUTINE INTEG (DELTA,G,N,RESULT)

C INCLUDES $N=1$

C IMPLICIT DOUBLE PRECISION $(A-H, O-Z)$

DIMENSION $G(8)$

NL1 $=N-1$

$N L 2=N-2$

IF (REAL (N) -2.0*REAL (N/2)) 100,100,10

10 If $(N-1) \quad 15,15,20$

15 SIGM $=0.0$

GO TO 70

20 IF $(N-3) 30,30,40$

30 si GM $=G(1)+4.0 * G(2)+G(3)$ 
GO TO 70

40 SUA $4=0.0$ DO $50 \quad K=2, N L Y, 2$

50 SUMG $=S U N_{4}+G(K)$

SUA2 $=0.0$

DO $60 \quad K=3, N L 2,2$

60 SUM $2=S U M 2+G(K)$

$S I G M A=G(1)+4.0 * \operatorname{SUN} 4+2.0 * S U M 2+G(N)$

70 RESULT $=$ DELTA*SI GMA

RETURN

100 I $F(N-2) 110,110,120$

$110 \operatorname{SIGM}=1.5 *(G(1)+G(2))$

GO TO 70

120 IF $(N-4) 130,130,140$

$130 \operatorname{SIGMA}=1.125 *(G(1)+3.0 * G(2)+3.0 * G(3)+G(4))$

GO TO 70

$140 \mathrm{IF}(\mathrm{N}-6) 150,150,160$

$150 \mathrm{SIGMA}=G(1)+3.875 * G(2)+2.625 * G(3)+2.625 * G(4)+3.875 * G(5)+G(6)$ GO TO 70

160 IF $(N-8) 170,170,180$

$170 \mathrm{SIGMA}=G(1)+3.875 * G(2)+2.625 * G(3)+2.625 * G(4)+3.875 * G(5)+2.0 \star G(6)$

$1+4.0 * G(7)+G(8)$ GO TO 70

$180 \mathrm{SIG}=G(1)+3.875 * G(2)+2.625 * G(3)+2.625 * G(4)+3.875 * G(5)+G(6)$

SUMA $=0.0$

DO $190 \quad K=7, N L 1,2$

190 SUM $4=$ SUM $4+G(K)$

SUM2 $=0.0$

DO $200 K=8, N L 2,2$

200 SUM $2=S U M 2+G(K)$

$S I G M A=S I G G+G(6)+4.0 * S U M 4+2.0 * S U M 2+G(N)$

GO TO 70

END

SUBROUTINE LOGO (VERSION)

$28 P R 94$.

CHARACTER VERSION*4, blue 10, green*7

CALL CLS

blue=CHAR (27)//' $\left[40 ; 36 ; 1 m^{\prime}\right.$

print 5 ,blue

5 format $(1 x, A)$

PRINT 10,',

10 FORMAT (a80)

PRINT 20

20 FORMAT $\left(6 x, r^{\prime}, 66\left({ }^{\prime}-{ }^{\prime}\right), y^{\prime}, 6\left(1^{\prime},\right)\right)$

PRINT 25

25 FORMAT $\left(6 x, x^{\prime} \mid, 66 x, x^{\prime}, 6\left(^{\prime} '\right)\right)$

PRINT 30

30 FORMAT $\left(6 X,\left.\right|^{\prime}, 27 X,{ }^{\prime}\right.$ SHIELDOSE-2',28X,' $\left.\mid{ }^{\prime}, 6\left(^{\prime}, '\right)\right)$

PRINT 25

PRINT 40

40 FORMAT (6x,'|', 15x, 'A Computer Code for Space-Shielding', 16x, '|', $16(1)$,

PRINT 50

50 FORMAT (6x,'|',19x,'Radiation Dose Calculations',20X,'|',6(' ')) PRINT 25

PRINT 60, VERSION

60 FORMAT (6x,' |',27x,' 'Version ',A,27x,' |',6(' '))

PRINT 25

PRINT 70

70 FORMAT $\left(6 x,\left.\right|^{\prime}, 28 x, '\right.$ 'Written by', 28x,' $\mid ', 6\left({ }^{\prime}\right.$ ' $)$ )

PRINT 80

80 FORMAT $\left(6 x,\left.\right|^{\prime}, 24 x,{ }^{\prime}\right.$ STEPHEN M. SELTZER',24X,' $\left.\mid ', 6\left(^{\prime} \prime \prime\right)\right)$

PRINT 90

90 FORMAT (6X, '|',10X, 'National Institute of standards and Technology $11,10 x, 1,6(1,1))$

PRINT 100

100 FORMAT (6X,'|',20X,'Gaithersburg, ND 20899, USA',19X,' |',6(' ')) PRINT 25

PRINT 110 


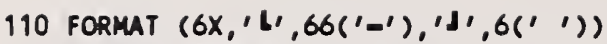

green $=$ CHAR (27)//' $\left[0 ; 32 \mathrm{~m}^{\prime}\right.$

print 5 ,green

RETURN

END

SUBROUTINE CLS

8 SEP 88.

c PRINT 10, CHAR (27)

10 FORMAT (' ',A1,'[2J')

RETURN

END 


\section{Appendix C. DOSCON Program Listing}

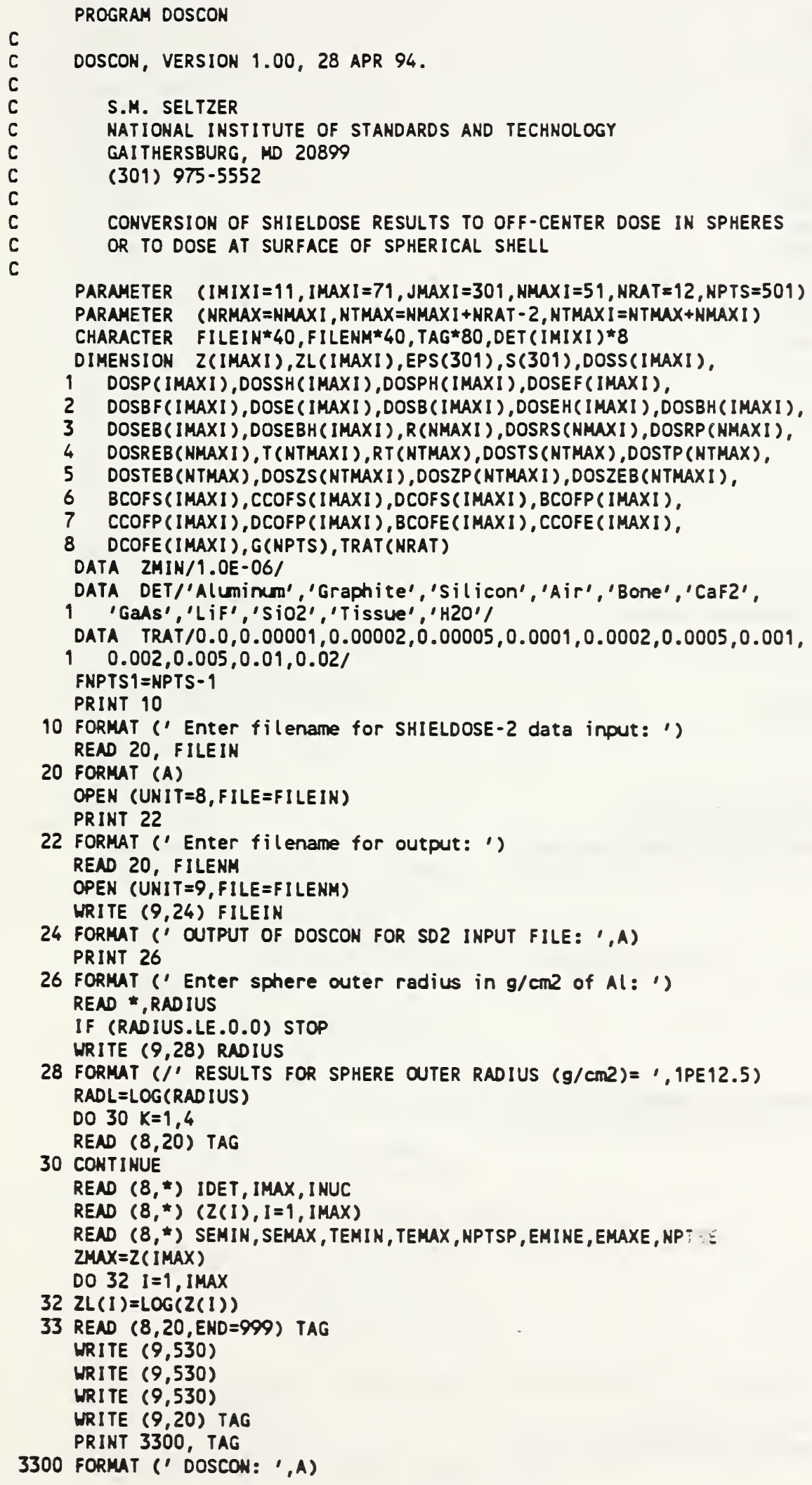


READ $(8$, *) JSMAX, JPMAX, JEMAX, EUNIT, OURATN

IF (JSMUX.LT.3) GO TO 34

$\operatorname{READ}(8, *)$ (EPS $(J), J=1, J S M A X)$

READ $(8, \star)(S(J), J=1, J S M A X)$

34 IF (JPMAX.LT.3) GO TO 36

$\operatorname{READ}(8, \star)$ (EPS $(J), J=1, J P M A X)$

$\operatorname{READ}(8, *)(S(J), J=1, J P M A X)$

36 IF (JEMAX.LT.3) GO TO 38

$\operatorname{READ}(8, *)$ (EPS $(J), J=1$, JEMAX)

READ $(8, *)(S(J), J=1$, JEMAX)

$38 \operatorname{READ}(8,40)$ (DOSS $(1), I=1$, IMAX)

$\operatorname{READ}(8,40)$ (DOSP $(1), 1=1,1$ MAX)

READ $(8,40)$ (DOSSH $(1), I=1, I M A X)$

$\operatorname{REND}(8,40)$ (DOSPH( $(1), I=1, I$ MAX)

$\operatorname{READ}(8,40)$ (DOSEF $(1), I=1, \operatorname{IMAX})$

$\operatorname{READ}(8,40)$ (DOSBF $(I), I=1, I$ IMAX)

$\operatorname{READ}(8,40)$ (DOSE $(1), i=1, I$ MAX)

$\operatorname{READ}(8,40)(\operatorname{DOSB}(1), I=1,1$ MAX)

$\operatorname{READ}(8,40)$ (DOSEH(I), I=1, IMAX)

$\operatorname{READ}(8,40)(D O S B H(I), I=1, I$ MAX)

40 FORMAT (IP 1OE10.3)

ISR $=1$

RMAX=MIN (RADIUS, ZMAX-RADIUS)

IF (RADIUS.GT.ZMAX) THEN

ISR $=0$

RMAX $=$ RADIUS

ENDIF

TMAX =RADIUS

IST $=1$

IF (RADIUS.GT.ZMAX) THEN

IST $=0$

ENDIF

TMAX=RADIUS* $(1.0-\operatorname{SQRT}(1.0-(Z M A X / R A D I U S) * 2))$

IF (JSHAX.GE.3) THEN

DO $60 \mathrm{I}=1$, IMAX

IF (DOSS(I).LE.0.0) 60 TO 65

$\operatorname{DOSS}(I)=\operatorname{LOG}(\operatorname{DOSS}(I))$

$60 \operatorname{DOSSH}(1)=\operatorname{LOG}(\mathrm{DOSSH}(1))$ 65 IMAXS $=1-1$

C

CALL SCOF (IMAXS, Z,DOSS,BCOFS,CCOFS,DCOFS)

C CALL BSPOL (0.0, IMAXS, 2, DOSS, BCOFS, CCOFS, DCOFS, ANS) DOSSO $=$ EXP (ANS)

ENDIF DOSSO $=\operatorname{EXP}(\operatorname{DOSS}(1))$

IF (JPMAX.GE.3) THEN

DO $70 \quad I=1$, IMAX

If $(\operatorname{DOSP}(1) . L E .0 .0)$ GO TO 75

$\operatorname{DOSP}(I)=\operatorname{LOG}(\operatorname{DOSP}(1))$

$70 \operatorname{DOSPH}(1)=\operatorname{LOG}(\operatorname{DOSPH}(1))$

I I IMAX+1

c IMAXP=I-1 CALL SCOF (IMAXP, Z,DOSP,BCOFP, CCOFP,DCOFP)

C CALL BSPOL ( 0.0 , IMAXP, $Z$, DOSP, BCOFP, CCOFP,DCOFP, ANS) DOSPO $=E X P$ (ANS) DOSPO $=\operatorname{EXP}(D O S P(1))$

ENDIF

IF (JEMNX.GE.3) THEN

DO $80 \quad I=1$, IMAX

$\operatorname{DOSEB}(I)=\operatorname{DOSE}(1)+\operatorname{DOSB}(I)$

DOSEBH $(I)=D O S E H(I)+D O S B H(I)$

IF (DOSEB(I).LE.0.0) GO TO 85

$\operatorname{DOSEB}(I)=\operatorname{LOG}(\operatorname{DOSEB}(I))$

$80 \operatorname{DOSEBH}(I)=\operatorname{LOG}(\operatorname{DOSEBH}(I))$

$I=I$ maX +1

85 IMAXE $=1-1$

C CALL SCOF (IMAXE,Z,DOSEB, BCOFE, CCOFE, DCOFE)

C CALL BSPOL ( 0.0 , IMAXE, $Z$, DOSEB, BCOFE, CCOFE, DCOFE, ANS)

C DOSEBO $=E X P$ (ANS) 


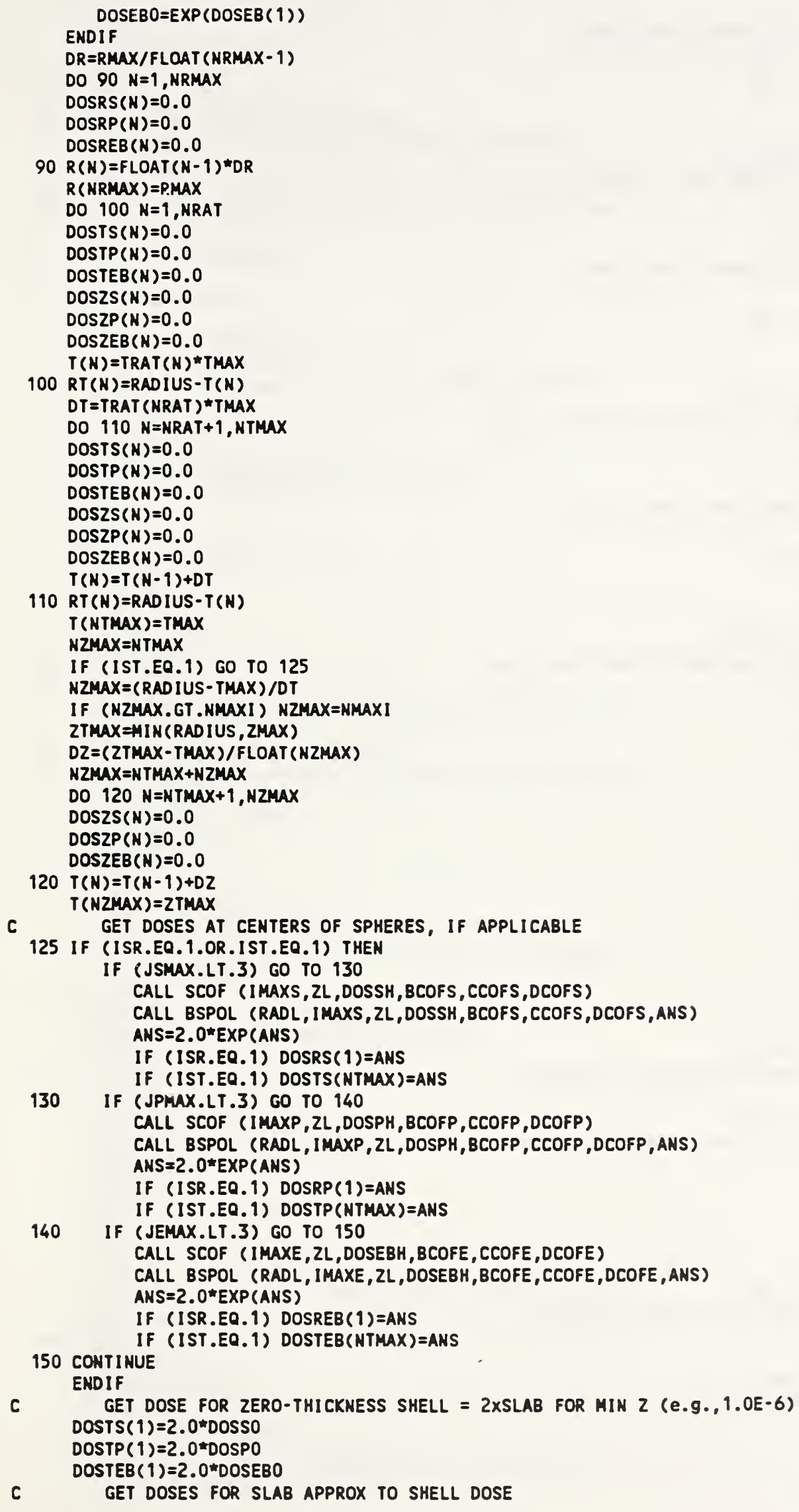


IF (JSHAX.LT.3) GO TO 180

CALL SCOF (IMAXS, ZL, DOSS, BCOFS, CCOFS, DCOFS)

DO $170 \mathrm{~N}=1$, NZMAX

IF (T(N).GT.0.0) GO TO 160

$\operatorname{DOSZS}(N)=\operatorname{DOSTS}(1)$

GO TO 170

$160 T L=\operatorname{LOG}(T(N))$

IF (TL.GT.ZL(IMAXS)) GO TO 170

CALL BSPOL (TL, IMAXS, ZL, DOSS, BCOFS, CCOFS, DCOFS, ANS)

$\operatorname{DOSZS}(N)=2.0^{\star} \operatorname{EXP}$ (ANS)

170 CONTINUE

180 IF (JPMAX.LT.3) GO TO 210

CALL SCOF (IMAXP, ZL, DOSP,BCOFP, CCOFP,DCOFP)

DO $200 \mathrm{~N}=1$, NZMAX

IF (T(N).GT.0.0) GO TO 190

$\operatorname{DOSZP}(\mathrm{N})=\operatorname{DOSTP}(1)$

GO TO 200

$190 \quad T L=\operatorname{LOG}(T(N))$

IF (TL.GT.ZL(IMAXP)) GO TO 200

CALL BSPOL (TL, IMAXP, ZL, DOSP, BCOFP, CCOFP, DCOFP, ANS)

$\operatorname{DOSZP}(\mathrm{H})=2.0{ }^{\star} \operatorname{EXP}($ ANS)

200 CONTINUE

210 IF (JEMAX.LT.3) GO TO 240

CALL SCOF (IMAXE,ZL,DOSEB, BCOFE, CCOFE,DCOFE)

DO $230 \mathrm{~N}=1$, NZMAX

IF (T(N).GT.0.0) GO TO 220

$\operatorname{DOSZEB}(N)=\operatorname{DOSTEB}(1)$

GO TO 230

$220 T L=\operatorname{LOG}(T(N))$

IF (TL.GT.ZL(IMAXE)) GO TO 230

CALL BSPOL (TL, IMAXE, ZL, DOSEB, BCOFE, CCOFE, DCOFE, ANS) $\operatorname{DOSZEB}(N)=2.0 * E X P(A N S)$

230 CONTINUE

C SPHERE INTEGRATIONS

240 IF (ISR.EQ.0) GO TO 370

DO $360 \mathrm{~N}=2$, NRMAX

RMR $=$ RAD IUS $-R(N)$

$R P R=R A D I U S+R(N)$

RPRL=LOG(RPR)

IF (JSMAX.LT.3) GO TO 280

DRMR $=0.0$

DRPR $=0.0$

IF (RMR.GT.ZMIN) GO TO 250

DRMR $=D O S S O$

RMR $=$ ZMIN

RMRL $=$ LOG (RMR)

GO TO 260

250 RMRL=LOG(RMR)

IF (RMRL.GT.ZL(IMAXS)) GO TO 260

CALL BSPOL (RMRL, IMAXS, ZL,DOSS, BCOFS, CCOFS, DCOFS, ANS) DRMR =EXP(ANS)

260 IF (RPRL.GT.ZL (IMAXS)) GO TO 265

CALL BSPOL (RPRL, IMAXS, ZL,DOSS, BCOFS, CCOFS, DCOFS, ANS) DRPR $=E X P$ (ANS)

265 DS $=($ RPRL - RMRL $) /$ FNPTS 1

DELTA $=D S / 3.0$

DO $270 \mathrm{NH}=1$, NPTS

$G(N M)=0.0$

$S L=R M R L+F L O A T(N N-1) * D S$

IF (SL.GT.ZL(IMAXS)) GO TO 270

CALL BSPOL (SL, IMAXS, ZL, DOSS, BCOFS, CCOFS, DCOFS, ANS)

$G(N N)=E X P(S L+A N S)$

270 CONTINUE

CALL INTEG (DELTA, G, NPTS, ANS)

DOSRS $(N)=($ RADIUS $*$ (DRMR-DRPR $)+A N S) / R(N)$

280 IF (JPMAX.LT.3) GO TO 320

DRMR $=0.0$

DRPR $=0.0$

IF (RMR.GT.ZMIN) GO TO 290 
$D R M R=D O S P O$

RMR $=$ ZMIN

RMRL $=\operatorname{LOG}$ (RMR)

GO TO 300

290 RMRL $=$ LOG (RMR)

IF (RMRL.GT.ZL(IMAXP)) GO TO 300

CALL BSPOL (RMRL, IMAXP, ZL, DOSP, BCOFP, CCOFP, DCOFP, ANS) DRMR $=$ EXP(ANS)

300 IF (RPRL.GT.ZL(IMAXP)) GO TO 305

CALL BSPOL (RPRL, IMAXP, ZL, DOSP, BCOFP, CCOFP, DCOFP, ANS) DRPR $=E X P($ ANS )

305 DS $=($ RPRL - RMRL $) / F N P T S$

$D E L T A=D S / 3.0$

DO $310 \mathrm{NN}=1$, NPTS

$G(N K)=0.0$

$S L=R M R L+F L O A T(N N-1) \star D S$

IF (SL.GT.ZL(IMAXP)) GO TO 310

CALL BSPOL (SL, IMAXP, ZL, DOSP, BCOFP, CCOFP, DCOFP, ANS)

$G(N N)=\operatorname{EXP}(S L+A N S)$

310 CONTINUE

CALL INTEG (DELTA, G, NPTS, ANS)

$\operatorname{DOSRP}(N)=\left(R A D I U S^{\star}(D R M R-D R P R)+A N S\right) / R(N)$

320 IF (JEMAX.LT.3) GO TO 360

DRMR $=0.0$

DRPR $=0.0$

IF (RMR.GT.ZMIN) GO TO 330

DRMR $=$ DOSEBO

RMR $=$ ZMIN

$R M R L=\operatorname{LOG}(R M R)$

GO TO 340

330 RMRL $=$ LOG (RMR)

IF (RMRL.GT.ZL(IMAXE)) GO TO 340

CALL BSPOL (RMRL, IMAXE, ZL, DOSEB, BCOFE, CCOFE, DCOFE, ANS) DRMR $=$ EXP(ANS)

340 IF (RPRL.GT.ZL (IMAXE)) GO TO 345

CALL BSPOL (RPRL, IMAXE, ZL, DOSEB , BCOFE, CCOFE, DCOFE, ANS) $D R P R=E X P$ (ANS)

345 DS= (RPRL -RMRL ) /FNPTS1

$D E L T A=D S / 3.0$

DO 350 NN=1, NPTS

$G(N N)=0.0$

$S L=R H R L+F L O A T(N N-1) * D S$

IF (SL.GT.ZL (IMAXE)) GO TO 350

CALL BSPOL (SL, IMAXE, ZL, DOSEB, BCOFE, CCOFE, DCOFE, ANS) $G(N N)=\operatorname{EXP}(S L+A N S)$

350 CONTINUE

CALL INTEG (DELTA,G,NPTS, ANS)

$\operatorname{DOSREB}(N)=($ RADIUS $*(D R M R-D R P R)+A N S) / R(N)$

360 CONTINUE

C SHELL INTEGRATIONS

370 DO $460 \mathrm{~N}=2$, NTMAX

IF (T(N).EQ.RADIUS) GO TO 460

$H=\operatorname{SQRT}(T(N) *(2.0 *$ RADIUS $-T(N)))$

$T L=\operatorname{LOG}(T(N))$

$H L=\operatorname{LOG}(H)$

IF (JSHAX.LT.3) GO TO 400

DRMR $=\operatorname{DOSZS}(\mathrm{N})$

$\mathrm{DH}=0.0$

IF (HL.GT.ZL(IMAXS)) GO TO 380

CALL BSPOL (HL, IMAXS, ZL,DOSS, BCOFS, CCOFS, DCOFS, ANS) $D H=E X P(A N S)$

380 DS $=(H L-T L) / F N P T S 1$

$D E L T A=D S / 3.0$

DO 390 NN $=1$, NPTS

$G(N N)=0.0$

$S L=T L+F L O A T(N N-1){ }^{*} D S$

IF (SL.GT.ZL(IMAXS)) GO TO 390

CALL BSPOL (SL, IMAXS, ZL,DOSS, BCOFS, CCOFS, DCOFS, ANS)

$G(N N)=\operatorname{EXP}(S L+A N S)$ 
390 CONTINUE

CALL INTEG (DELTA, G, NPTS, ANS)

DOSTS $(N)=\left(\right.$ RADIUS*DRMR $\left.-2.0^{\star}\left(H^{\star} D H-A N S\right)\right) / R T(N)$

400 IF (JPMAX.LT.3) GO TO 430

$D R M R=D O S Z P(N)$

$D H=0.0$

IF (HL.GT.ZL(IMAXP)) GO TO 410

CALL BSPOL (HL, IMAXP, ZL, DOSP, BCOFP, CCOFP, DCOFP, ANS)

$D H=E X P(A N S)$

410 DS $=(H L-T L) / F N P T S 1$

$D E L T A=D S / 3.0$

DO 420 NN $=1$, NPTS

$G(N N)=0.0$

$S L=T L+F L O A T(N N-1) \star D S$

IF (SL.GT.ZL(IMAXP)) GO TO 420

CALL BSPOL (SL, IMAXP, ZL, DOSP, BCOFP, CCOFP, DCOFP, ANS)

$G(N N)=\operatorname{EXP}(S L+A N S)$

420 CONTINUE

CALL INTEG (DELTA, G, NPTS, ANS)

$\operatorname{DOSTP}(N)=\left(\right.$ RADIUS $\left.{ }^{\star D R M R}-2.0^{*}\left(H^{\star} D H-A N S\right)\right) / R T(N)$

430 IF (JEMAX.LT.3) GO TO 400

$D R M R=D O S Z E B(N)$

$D H=0.0$

IF (HL.GT.ZL(IMAXE)) GO TO 440

CALL BSPOL (HL, IMAXE, ZL, DOSEB, BCOFE, CCOFE, DCOFE, ANS) $D H=\operatorname{EXP}$ (ANS)

440 DS $=(H L-T L) / F N P T S 1$

DELTA $=D S / 3.0$

DO 450 NN=1, NPTS

$G(N K)=0.0$

$S L=T L+F L O A T(N N-1) \star D S$

IF (SL.GT.ZL (IMAXE)) GO TO 450

CALL BSPOL (SL, IMAXE, ZL, DOSEB, BCOFE, CCOFE, DCOFE, ANS)

$G(N N)=\operatorname{EXP}(S L+A N S)$

450 CONTINUE

CALL INTEG (DELTA, G, NPTS, ANS)

$\operatorname{DOSTEB}(N)=\left(\right.$ RADIUS*DRMR $\left.-2.0 *\left(H^{*} D H-A N S\right)\right) / R T(N)$

460 CONTINUE

IF (ISR.EQ.0) GO TO 560

WRITE $(9,500)$

500 FORMAT ( $/$ ' DOSE AS A FUNCTION OF RADIUS $r$ IN A SOLID SPHERE') WRITE $(9,510)$ DET (IDET)

510 FORMAT (/' rads ',A)

WRITE $(9,520)$

520 FORMAT ( $/ 1, \mathrm{r}(\mathrm{g} / \mathrm{cm} 2)$ EL+BR TRP PROT SOL PROT EL+BR+TRP

(TOTAL')

WRITE $(9,530)$

530 FORMAT $(1,1)$

DO $550 N=1$, NRMAX

DOSEBP $=$ DOSREB $(N)+D O S R P(N)$

DOST $=$ DOSEBP + DOSRS $(N)$

WRITE (9,540) R(N),DOSREB ( $N), D O S R P(N), D O S R S(N), D O S E B P, D O S T$

540 FORMAT (2(OPF11.5, 1P5E10.2))

550 CONTINUE

560 WRITE $(9,600)$

600 FORMAT (/' DOSE AT INHER SURFACE, AT RADIUS $r$, IN A SPHERICAL SHEL IL')

WRITE $(9,610)$

610 FORMAT (" THICE THE DOSE IS GIVEN ALSO AT EDGE OF PLANE SLAB OF S TAME THICKNESS $t$ AS SHELL')

WRITE $(9,510)$ DET(IDET)

WRITE $(9,615)$

615 FORMAT (/)

$10 . .$.

SPHERICAL SHELL

2')

WRITE $(9,620)$

620 FORMAT (' $r(\mathrm{~g} / \mathrm{cm} 2)$ EL+BR TRP PROT SOL PROT EL+BR+TRP ITOTAL $t(g / \mathrm{cm} 2)$ EL+BR TRP PROT SOL PROT EL+BR+TRP TOTAL 2') 
WRITE $(9,530)$

DO $650 \mathrm{~N}=1$, NTMAX

DOSEBP $=$ DOSTEB $(N)+D O S T P(N)$

$D O S T=D O S E B P+D O S T S(N)$

DUSEBP $=D O S Z E B(N)+D O S Z P(N)$

DUST $=$ DUSEBP + DOSZS $(N)$

WRITE (9,540) RT(N),DOSTEB(N),DOSTP(N), DOSTS (N), DOSEBP,DOST,

1

650 CONTINUE

IF (NZMAX.EQ.NTMAX) GO TO 33

DO $670 N=N T M A X+1$, NZMAX

DUSEBP $=D O S Z E B(N)+D O S Z P(N)$

DUST $=$ DUSEBP + DOSZS $(\mathrm{N})$

WRITE $(9,660) T(N), D O S Z E B(N), D O S Z P(N), D O S Z S(N), D U S E B P, D U S T$

660 FORMAT ( $61 X, 0 P F 11.5,1$ IPE 10.2)

670 CONTINUE

GO TO 33

999 STOP

END

SUBROUTINE $S C O F(N, X, Y, B, C, D)$

C REINSCH ALGORITHM, VIA MJB, 22 FEB 83

C $\quad Y(S)=((D(J) \star(X-X(J))+C(J)) *(X-X(J))+B(J)) \star(X-X(J))+Y(J)$

C FOR $X$ BETWEEN $X(J)$ AND $X(J+1)$

C IMPLICIT DOUBLE PRECISION $(A-H, O-Z)$

DIMENSION $X(1), Y(1), B(1), C(1), D(1)$

$\mathrm{N} 1=\mathrm{N}-1$

$S=0.0$

DO $10 \mathrm{~J}=1, \mathrm{N1}$

$D(J)=X(J+1)-X(J)$

$R=(Y(J+1)-Y(j)) / D(J)$

$C(J)=R-S$

$10 \mathrm{~S}=\mathrm{R}$

$S=0.0$

$R=0.0$

$C(1)=0.0$

$C(\mathrm{~N})=0.0$

DO $20 \quad J=2, N 1$

$C(J)=C(J)+R \star C(J-1)$

$B(J)=(X(J-1) \cdot X(J+1)) \star 2.0-R \star S$

$S=D(J)$

$20 R=S / B(J)$

DO $30 \mathrm{JR}=\mathrm{N} 1,2,-1$

$30 C(J R)=(D(J R) \star C(J R+1)-C(J R)) / B(J R)$

$D O 4 O \mathrm{~J}=1, \mathrm{N1}$

$S=D(J)$

$R=C(7+1)-C(7)$

$D(J)=R / S$

$C(J)=3.0 * C(J)$

$40 B(J)=(Y(J+1)-Y(J)) / S-(C(J)+R) \approx S$

RETURN

END

SUBROUTINE BSPOL $(S, N, X, Y, B, C, D, T)$

BINARY SEARCH, $X$ ASCENDING OR DESCENDING

C

IMPLICIT DOUBLE PRECISION $(A-H, O-Z)$

DIMENSION $X(1), Y(1), B(1), C(1), D(1)$

IF $(X(1) . G T . X(N))$ GO TO 10

$I D I R=0$

$M L B=0$

MUB $=\mathrm{N}$

GO TO 20

10 IDIR=1

$M L B=N$

MUB $=0$

20 IDIRI = IDIR-1

IF (S.GE.X(MUB+IDIR)) GO TO 60

IF (S.LE.X(MLB-IDIRI)) GO TO 70

$M L=A L B$

$M U=1 M B$

GO TO 40 


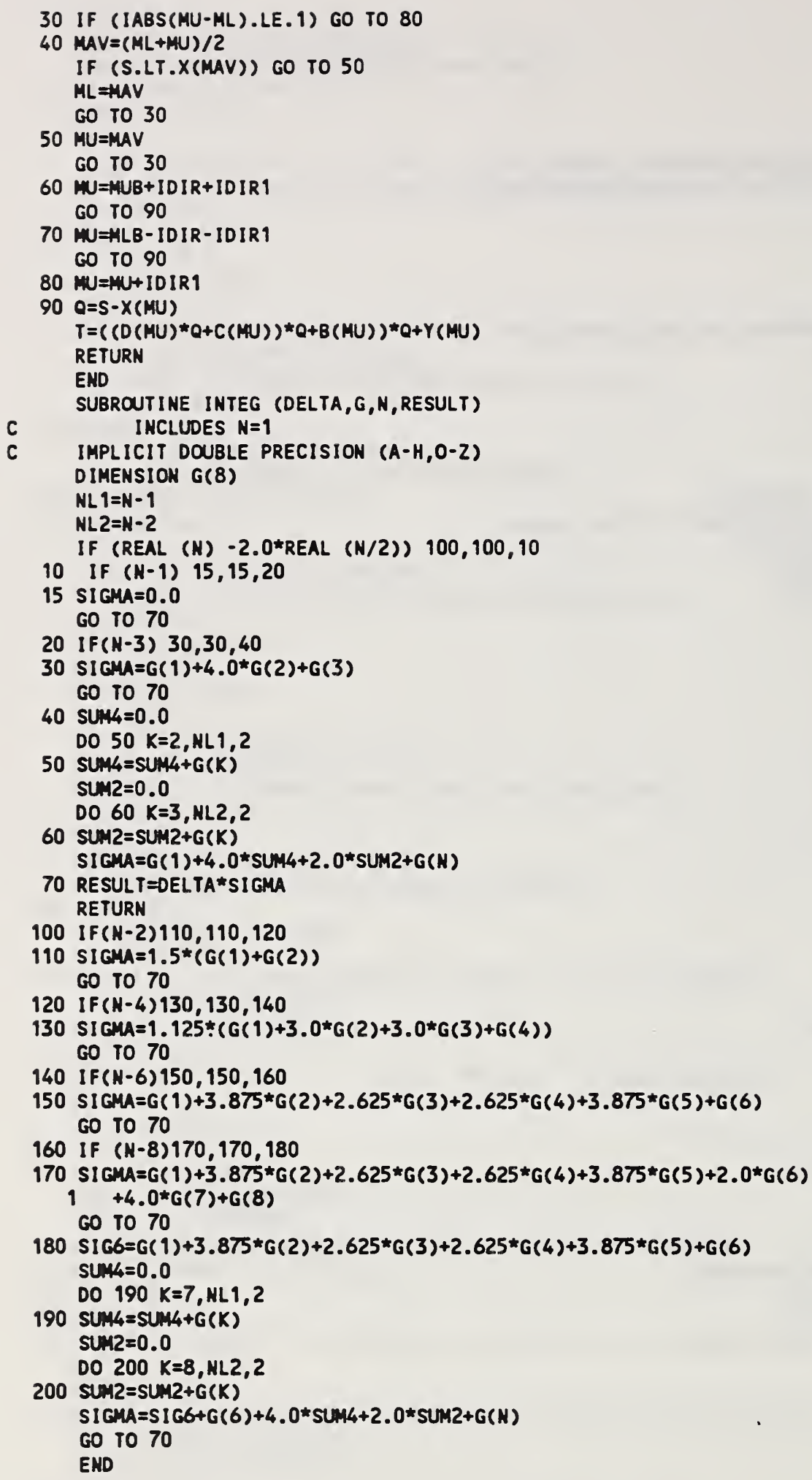




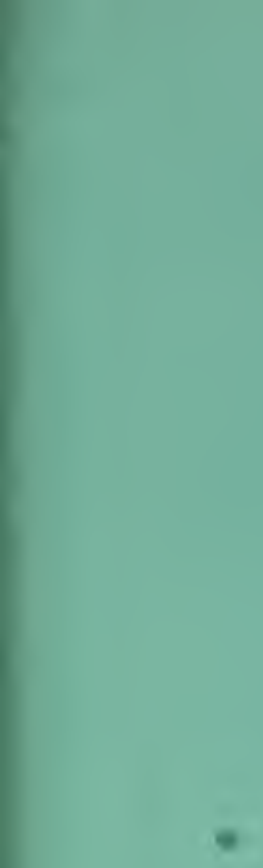


